\title{
p75NTR and DR6 Regulate Distinct Phases of Axon Degeneration Demarcated by Spheroid Rupture
}

\author{
Yu Yong, ${ }^{1 \star}$ - Kanchana Gamage, ${ }^{3,5 \star}$ Irene Cheng, ${ }^{1,2}$ Kelly Barford, ${ }^{2}$ Anthony Spano, ${ }^{1}{ }^{\circledR B}$ Bettina Winckler, ${ }^{3}$ \\ and Christopher Deppmann $n^{1,2,3,4}$ \\ ${ }^{1}$ Department of Biology, ${ }^{2}$ Neuroscience Graduate Program, ${ }^{3}$ Department of Cell Biology, ${ }^{4}$ Department of Biomedical Engineering, University of Virginia, \\ Charlottesville, Virginia 22903, and ${ }^{5}$ Amgen, Massachusetts \& Department of Stem Cell and Regenerative Biology, Harvard University, Cambridge, \\ Massachusetts 02138
}

The regressive events associated with trophic deprivation are critical for sculpting a functional nervous system. After nerve growth factor withdrawal, sympathetic axons derived from male and female neonatal mice maintain their structural integrity for $\sim 18 \mathrm{~h}$ (latent phase) followed by a rapid and near unison disassembly of axons over the next $3 \mathrm{~h}$ (catastrophic phase). Here we examine the molecular basis by which axons transition from latent to catastrophic phases of degeneration following trophic withdrawal. Before catastrophic degeneration, we observed an increase in intra-axonal calcium. This calcium flux is accompanied by p75 neurotrophic factor receptor-Rho-actindependent expansion of calcium-rich axonal spheroids that eventually rupture, releasing their contents to the extracellular space. Conditioned media derived from degenerating axons are capable of hastening transition into the catastrophic phase of degeneration. We also found that death receptor 6, but not p75 neurotrophic factor receptor, is required for transition into the catastrophic phase in response to conditioned media but not for the intra-axonal calcium flux, spheroid formation, or rupture that occur toward the end of latency. Our results support the existence of an interaxonal degenerative signal that promotes catastrophic degeneration among trophically deprived axons.

Key words: degeneration; DR6; p75NTR; pruning; spheroids

\section{Significance Statement}

Developmental pruning shares several morphological similarities to both disease- and injury-induced degeneration, including spheroid formation. The function and underlying mechanisms governing axonal spheroid formation, however, remain unclear. In this study, we report that axons coordinate each other's degeneration during development via axonal spheroid rupture. Before irreversible breakdown of the axon in response to trophic withdrawal, p75 neurotrophic factor receptor-RhoA signaling governs the formation and growth of spheroids. These spheroids then rupture, allowing exchange of contents $\leq 10 \mathrm{kDa}$ between the intracellular and extracellular space to drive death receptor 6 and calpain-dependent catastrophic degeneration. This finding informs not only our understanding of regressive events during development but may also provide a rationale for designing new treatments toward myriad neurodegenerative disorders.

\section{Introduction}

Throughout nervous system development, axons, synapses, and even entire neurons are initially overproduced and then refined

Received Aug. 1, 2019; revised Sept. 11, 2019; accepted 0ct. 13, 2019

Author contributions: Y.Y., K.G., and C.D. designed research; Y.Y., K.G., I.C., K.B., and A.S. performed research; Y.Y., K.G., B.W., and C.D. analyzed data; Y.Y. wrote the first draft of the paper; Y.Y., K.G., B.W., and C.D. edited the paper; Y.Y. and C.D. wrote the paper.

This work was supported by National Institutes of Health-National Institute of Neurological Disorders and Stroke Grant R01NS091617 and the Owens Family Foundation to C.D. We thank Pamela Neff, Elena Tenore, Nadine Ly, and Courtney Cushman for technical assistance; Austin Keeler, Sushanth Kumar, Shayla Clark, Amrita Pathak, Vitaly Zimyanin, and Brandon Podyma for helpful discussions and comments on the manuscript; Xiaorong Liu, Barry Condron, and Ali Guler for helpful comments on the manuscript; Ammasi Periasamy and the Keck Center for Cellular Imaging for the usage of the Leica SP5X microscopy system (RR025616); Genentech for kindly providing the through a period of organized culling (Purves and Lichtman, 1980; Hamburger and Oppenheim, 1990; Kantor and Kolodkin, 2003). Sympathetic neurons in the PNS rely on NGF-TrkA neurotrophic signaling to stabilize these components (Hendry and Campbell, 1976; Campenot, 1977; Purves et al., 1988; Yan et al., 2010; Gamage et al., 2017). The absence of sufficient neurotrophic

\footnotetext{
DR6 ${ }^{-/-}$mouse line; and Bruce Carter (Vanderbilt University) for providing the p75NTR functional blocking 9650 antibody.

The authors declare no competing financial interests.

*Y.Y. and K.G. contributed equally to this work.

Correspondence should be addressed to Christopher Deppmann at deppmann@virginia.edu.

https://doi.org/10.1523/JNEUROSCI.1867-19.2019

Copyright $\odot 2019$ the authors
} 
signaling permits prodestructive cues originating from TNF receptor superfamily members, such as p75 neurotrophin receptor (p75NTR), death receptor 6 (DR6), and TNF receptor 1a, to promote regressive events, such as cell death, synapse restriction, or axon degeneration in the PNS (Singh et al., 2008; Nikolaev et al., 2009; Olsen et al., 2014; Wheeler et al., 2014; Gamage et al., 2017). Axon degeneration is critical for proper nervous system wiring during development, but it is also a hallmark of several neural pathologies, such as Alzheimer's disease, amyotrophic lateral sclerosis, and injury (Saxena and Caroni, 2007). Both developmental and pathological degeneration occurs in two phases: latent and catastrophic (Wang et al., 2012; Kristiansen and Ham, 2014).

During latent phase, axons are morphologically indistinguishable from those receiving trophic support (Deckwerth and Johnson, 1993). Readdition of trophic factor or mild depolarization during the latent phase is capable of rescuing degeneration (Edwards et al., 1991). After latency, the catastrophic/execution stage of degeneration occurs in a rapid and near synchronous manner. During this period, axonal transport ceases, axons develop swellings, neurofilaments become fragmented, the cytoskeleton disintegrates, and debris is removed by recruited phagocytes (Luo and O'Leary, 2005; Saxena and Caroni, 2007). Importantly, this stage of degeneration represents the point of no return where reintroduction of neurotrophic factors does not rescue degeneration (Edwards et al., 1991). Although we and others have shown that, in the absence of NGF-TrkA signaling, p75NTR and DR6 mediate axon degeneration (Bamji et al., 1998; Singh et al., 2008; Nikolaev et al., 2009; Olsen et al., 2014; Gamage et al., 2017), the relative contributions of p75NTR and DR6 specifically to latent and catastrophic phases of degeneration have largely been overlooked.

How do axons transition from latent to catastrophic phases? It was shown that calcium signaling in degenerating axons promotes activation of calpain, the calcium-sensitive protease required for the disassembly of cytoskeletal elements (George et al., 1995; Avery et al., 2012; Vargas et al., 2015). During development, it is thought that compartmentalized calcium transients act as temporal and spatial cues to trigger dendrite pruning (Kanamori et al., 2013). Moreover, it was recently shown that axoplasmic calcium increases before the emergence of gross morphological changes in NGF-deprived DRG cultures (Johnstone et al., 2019), suggesting that intra-axonal calcium signaling could play a role in all phases of degeneration. However, whether death receptors act permissively to allow calcium-dependent irreversible fragmentation in response to trophic withdrawal remains an open question.

In this study, we demonstrate that, after trophic deprivation, intra-axonal calcium increases before catastrophic degeneration. This is accompanied by the formation of calcium-rich spheroids that grow and then rupture, releasing their contents $(\leq 10 \mathrm{kDa})$ to the extracellular space while allowing an influx of extracellular molecules (e.g., calcium) into the intra-axonal space. The prodegenerative molecules released into the extracellular space are capable of hastening entry of trophically deprived axons into the catastrophic phase of degeneration. We show that p75NTR promotes spheroid formation, intra-axonal calcium rise, and membrane rupture in a Rho-dependent manner. In contrast, DR6 is not required for spheroid formation and rupture. Moreover, DR6 is required to hasten entry into the catastrophic phase of degeneration in response to conditioned media from degenerating axons, whereas p75NTR is dispensable. Together, these data place p75NTR and DR6 upstream and downstream of spheroidal rupture, respectively. This is consistent with separable roles for these receptors in early and late phases of degeneration induced by trophic withdrawal.

\section{Materials and Methods}

Mice. All experiments were performed in compliance with the Association for Assessment of Laboratory Animal Care policies and approved by the University of Virginia Animal Care and Use Committee. All mice are on a C57BL/6J.129S mixed background. $p 75 \mathrm{NTR}^{-/-}$animals were purchased from The Jackson Laboratory. $D R 6^{-1-}$ animals were a generous gift from Genentech. Males and females are mixed in all of our experiments.

Primary sympathetic neuronal cultures. Sympathetic neuron cultures were established as described previously (Deppmann et al., 2008). Briefly, neurons were obtained by dissociation of $\mathrm{P} 0-\mathrm{P} 2$ mouse superior cervical ganglia. These neurons (from each litter of pups) were plated in compartmentalized microfluidic devices in DMEM supplemented with $10 \% \mathrm{FBS}$, penicillin/streptomycin $(1 \mathrm{U} / \mathrm{ml})$, and $45 \mathrm{ng} / \mathrm{ml}$ of NGF purified from mouse salivary glands. Glia are removed from cultures using 5 $\mu \mathrm{M}$ cytosine arabinofuranoside (Sigma-Aldrich) for $48-72 \mathrm{~h}$. For NGF deprivation, cultures were washed three times with media lacking NGF and then maintained in NGF-deficient media containing a neutralizing antibody ( $1 \mu \mathrm{g} / \mathrm{ml}$ anti-NGF antibody, Millipore) through designated time points at $37^{\circ} \mathrm{C}$.

Fabrication and use of microfluidic devices. Microfluidic devices were generated as described previously (Park et al., 2006). These chambers were affixed to coverglass coated with poly-D-lysine $(50 \mu \mathrm{g} / \mathrm{ml})$ and laminin $(1 \mu \mathrm{g} / \mathrm{ml})$.

Immunocytochemistry. Immunocytochemistry was performed as previously described (Singh et al., 2008). Briefly, at the indicated times, axons were fixed in $4 \% \mathrm{PFA}(\mathrm{w} / \mathrm{v}) / \mathrm{PBS}$ at room temperature for $20 \mathrm{~min}$, washed $3 \times 5$ min with $1 \times \mathrm{PBS}$, and blocked/permeabilized (5\% goat serum, $0.05 \%$ Triton $\mathrm{X}-100$ in PBS) for $1 \mathrm{~h}$ at room temperature. Axons were then incubated overnight at $4^{\circ} \mathrm{C}$ with primary antibody diluted in blocking buffer. Cells were then washed $3 \times 5$ min with $1 \times$ PBS and incubated with fluorescent secondary antibody for $1 \mathrm{~h}$ at room temperature. Cells were again washed with $1 \times$ PBS three times and imaged using a fluorescent inverted microscope. The antibodies used in this study are mouse anti-Tuj1 (1:1000, Covance) and goat anti-mouse Alexa-488 (1: 800 , Invitrogen). For active Rho staining, axons were incubated with 50 $\mu \mathrm{g} / \mathrm{ml}$ of GST-Rhotekin-Rho binding domain (RBD) fusion protein in blocking solution for $1 \mathrm{~h}$ at room temperature, washed $3 \times 5$ min with $1 \times$ PBS. Cells were then incubated with anti-GST (1:800, Sigma-Aldrich, G1160) diluted in blocking buffer for $1 \mathrm{~h}$, washed $3 \times 5 \mathrm{~min}$ with $1 \times \mathrm{PBS}$, and incubated with fluorescent secondary antibody for $1 \mathrm{~h}$ at room temperature. All in vitro experiments were performed in triplicate with at least two microfluidic devices used for each condition.

Live imaging. Sympathetic neuron cultures were washed 3 times with DMEM/F-12, Phenol Red free, and incubated for $30 \mathrm{~min}$ at $37^{\circ} \mathrm{C}$ and $10 \% \mathrm{CO}_{2}$ with live imaging dyes diluted in DMEM/F-12, Phenol Red free. Cells were then imaged under Leica SP5 X confocal microscope in W.M. Keck Center at the University of Virginia. Axons in grooves of microfluidic chamber were imaged after NGF deprivation. For assessing flipping of phosphatidylserine (PS) on axonal spheroids, Annexin V red reagent (IncuCyte, 4641) was diluted in DMEM/F-12, Phenol Red free (1:200) after NGF deprivation. For membrane rupture, dextran dyes diluted in DMEM/F-12, Phenol Red free were added to the microfluidic chamber after $17 \mathrm{~h}$ of NGF deprivation. The dyes used in this study are Fluo-4 AM (1 $\mu \mathrm{M}, \mathrm{F} 14201)$ and Dextran Texas Red, neutral, $3 \mathrm{kDa}(50$ $\mu \mathrm{M}, \mathrm{D} 3329), 10 \mathrm{kDa}(50 \mu \mathrm{M}, \mathrm{D} 1828)$, and $70 \mathrm{kDa}(50 \mu \mathrm{M}, \mathrm{D} 1830)$. All dyes were purchased from Thermo Fisher Scientific. Drugs used for manipulating spheroid formation are Z-VAD-FMK (50 $\mu \mathrm{M}$, Enzo, ALX260-020), calpain inhibitor III (20 $\mu \mathrm{M}$, Millipore, 208722), actinomycin D (1 $\mu \mathrm{g} / \mathrm{ml}$, Sigma-Aldrich, A9415), CT04 (1 $\mu \mathrm{g} / \mathrm{ml}$, Cytoskeleton), cytochalasin D (10 $\mu \mathrm{g} / \mathrm{ml}$, Sigma-Aldrich, C2618), CN03 (1 $\mu \mathrm{g} / \mathrm{ml}$, Cytoskeleton Inc), LM11A-31 (2 ng/ml, Cayman Chemicals, 21982), and anti-BDNF (20 $\mu \mathrm{g} / \mathrm{ml}$, Millipore, AB1779SP); 9650 immune serum was a gift from Bruce Carter in Vanderbilt University.

Image processing and analysis. Axon degeneration in culture was quantified from $\beta 3$-tubulin-stained fluorescence images by counting the number of individual axons at the leading edge that had at least three 
beads/blebs as described previously (Zhai et al., 2003). A blinded investigator counted 10 representative pictures of the axons, in two microfluidic chambers per condition/time point. On each image, $1050 \mu \mathrm{m}$ boxes were randomly assigned to single axons. The investigator took care not to box bundles of axons, which may confound analysis. Then the number of boxes, which had $\geq 3$ beads/blebs were counted and categorized as degenerating axons; $\geq 80 \%$ degeneration was considered maximum degeneration, and equal to or $<10 \%$ degeneration of axons was considered as minimum degeneration. The percentage of the total number of degenerating axons was calculated using Microsoft Excel. At least 300 total axons were counted for each condition. The SEM was considered as error. In live imaging, $\mathrm{Ca}^{2+}$ intensity $(\Delta \mathrm{F} / \mathrm{F} 0)$, the size $(\mathrm{S} / \mathrm{S} 0)$, and number of axonal spheroids were quantified in selected ROI (single axon or axonal spheroid) by Fiji software (Schindelin et al., 2012). Each experiment was repeated at least 3 times with separate litters of mouse pups of the same genotype.

Conditioned media experiments. Established compartmentalized recipient neuron cultures were deprived of NGF by washing with NGF-free DMEM three times and incubating at $37^{\circ} \mathrm{C}$ with a neutralizing anti-NGF antibody for $12 \mathrm{~h}$. To collect NGF deprivation conditioned media (NDCM), donor neuron cultures were washed with NGF-free DMEM three times and treated with a neutralizing anti-NGF antibody at $37^{\circ} \mathrm{C}$ for $24 \mathrm{~h}$. For each device, a volume of $\sim 100 \mu \mathrm{l}$ of NDCM was collected, including the media in the wells of the device on the axonal side and the media in the axonal channel. NDCM or control conditioned media were applied on recipient axons for $5 \mathrm{~h}$.

Calcium measurement. Conditioned media were diluted to MilliQ water (1:20) and mixed thoroughly; $100 \mu \mathrm{l}$ of reaction mixture was made with $1 \mu \mathrm{l}$ HEPES, $2 \mu \mathrm{l} 1 \mathrm{~mm}$ Fluo-4 (20 mm working concentration, Invitrogen), $10 \mu \mathrm{l}$ diluted conditioned media, and $87 \mu \mathrm{l}$ water. Black 96-well plate was used in spectrophotometric assay. Eight $\mathrm{CaCl}_{2}$ standards $(2.54,4.87,9.75,19.5,39,78,156$, and $313 \mu \mathrm{M})$ were used to calculate standard curve for analyzing $\mathrm{Ca}^{2+}$ concentration in conditioned media.

Exogenous calcium assay. Sympathetic neuron cultures were washed three times with DMEM supplemented with $10 \%$ FBS, penicillin/streptomycin $(1 \mathrm{U} / \mathrm{ml})$, and then incubated in NGF-deficient media containing a neutralizing antibody ( $1 \mu \mathrm{g} / \mathrm{ml}$ anti-NGF antibody, Millipore) for $12 \mathrm{~h}$. For exogenous calcium concentration $<1.8 \mathrm{~mm}$ (DMEM), cells were washed 3 times with DMEM Ca ${ }^{2+}$-free media. $\mathrm{CaCl}_{2}$ was added to DMEM $\mathrm{Ca}^{2+}$-free media to indicated final concentrations, which was then applied to cultures $37^{\circ} \mathrm{C}$ and $10 \% \mathrm{CO}_{2}$ for $5 \mathrm{~h}$.

Experimental design and statistical analysis. Statistical analysis was performed in Prism 8.0 software (GraphPad). All measurements are shown as mean \pm SEM. For samples defined by one factor, data were compared by unpaired two-tailed $t$ tests for two samples or one-way ANOVA with Tukey's post hoc multiple-comparisons test for $\geq 3$ samples. For samples defined by two factors, data were compared by two-way ANOVA with Sidak's post hoc multiple-comparisons test. Sample size $(n)$ was defined as the number of axons or axonal spheroids counted in live imaging experiment, or the number of independent cultures that were quantified in each experiment. The null hypothesis was rejected at the 0.05 level. $p$ values $<0.05$ are considered significant. The statistical test, sample size $(n)$, and the $p$ values are reported in the figure legends.

\section{Results}

\section{Intra-axonal calcium increases in trophic factor-deprived axons and accumulates in spheroids before catastrophic degeneration}

To study the kinetics of degeneration induced by trophic withdrawal, we cultured sympathetic neurons from P0-P2 mice in microfluidic devices, which separate soma and axons (Fig. 1A). After establishment in $45 \mathrm{ng} / \mathrm{ml}$ of NGF for 5-7 DIV, WT sympathetic neurons were globally or locally deprived of NGF with media containing anti-NGF function blocking antibody for indicated times. After global NGF deprivation, the majority of axons remain intact for $\sim 18 \mathrm{~h}$ as measured by microtubule integrity ( $\beta 3$-tubulin staining). This period of sustained axonal integrity is referred to as the latent phase of degeneration (Coleman, 2005). At the conclusion of the latent phase, the majority of axons rapidly degenerate from $4.4 \pm 1.5 \%$ to $90.4 \pm 2.2 \%$ of degeneration within $3 \mathrm{~h}$ (Fig. $1 B, C)$. This is referred to as the catastrophic or execution phase of degeneration (Wang et al., 2012).

What are the molecular events that signal the transition from latent to catastrophic phase? Axonal calcium waves have been reported to be critical in promoting axon degeneration after axotomy (Vargas et al., 2015). Given the importance of the calcium-dependent protease, calpain, in developmental axon degeneration, we speculated that calcium waves may occur at the transition between latent and catastrophic phases (Yang et al., 2013). We examined axonal calcium dynamics using Fluo4-AM imaging of axons that were withdrawn from NGF. Multiple small calcium peaks were detected during the first $12 \mathrm{~h}$, while the largest axoplasmic calcium flux that we observed occurred between 17 and $19 \mathrm{~h}$ after global trophic withdrawal (Fig. 1D), a time reflecting the transition window between latent and catastrophic phases (Fig. 1C). Notably, axonal calcium increases up to threefold over baseline by $17 \mathrm{~h} 50 \mathrm{~min}$ after global NGF deprivation (Fig. $1 F$ ). After this initial increase, axonal calcium levels decrease $\sim 1.5$-fold. We hypothesize that axonal calcium increase may be a hallmark of the transition between latent and catastrophic degeneration phases.

In addition to axonal apoptosis induced by global NGF deprivation, pruning is critical for refinement of the nervous system during development. To examine whether axon pruning has similar calcium dynamics in relation to degeneration kinetics, we selectively deprived NGF in the axon compartment of sympathetic neurons grown in microfluidic devices (Fig. 1A). The majority of axons remain intact until $46 \mathrm{~h}$ after local NGF deprivation, indicating the delayed latent phase compared with global NGF deprivation, which is consistent with previous reports (Chen et al., 2012) (Fig. 1 B,C). Calcium levels in locally NGFdeprived axons spiked before entry into the catastrophic phase of degeneration (Fig. 1D). This relationship between calcium spike and catastrophic degeneration is similar to what we observed in neurons globally deprived of NGF, albeit with an overall delay in degeneration kinetics.

Upon closer inspection of calcium dynamics within the entire axon, we observed that much of this calcium is concentrated in nascent spheroids on NGF-deprived axons (Fig. 1E). The formation of axonal spheroids/beads has been observed in not only trophic withdrawal models of developmental degeneration but also in pathological scenarios (Takahashi et al., 1997; Griffiths et al., 1998; Probst et al., 2000; Beirowski et al., 2010; Mejia Maza et al., 2019). However, whether these beads/spheroids have a function as degeneration progresses remains an open question. Interestingly, after observing the initial formation of calcium-rich spheroids, these structures increase in size from $4.1 \pm 0.5 \mu \mathrm{m}^{2}$ to $19.6 \pm 2.7 \mu \mathrm{m}^{2}(\sim 500 \%)$ within $1 \mathrm{~h}$ (Fig. $1 G$ ). In addition to the increase in average spheroid size, the number of spheroids increased from 1 to 13 per $100 \mu \mathrm{m}$ between 17 and $18 \mathrm{~h}$ after trophic withdrawal (Fig. $1 H$ ). Spheroidal calcium levels had a $\sim 1.7$-fold increase by $17 \mathrm{~h} 50 \mathrm{~min}$ after NGF deprivation (Fig. $1 G)$. However, the spheroidal calcium levels varied depending on spheroid size. This value likely underestimates the increase in calcium since the spheroidal area measured increases with time. As such, we also normalized the areas used for the ROI to quantify the spheroidal calcium density and found the same trend (Fig. 1I).

To determine whether intra-axonal calcium elevation is required for the formation of spheroids, we depleted axoplasmic calcium by BAPTA-AM and examined the morphological 
A

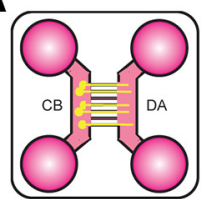

Microfluidic system

C

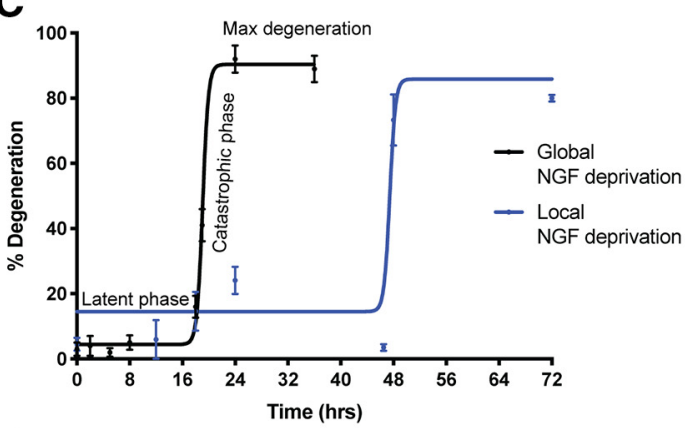

D
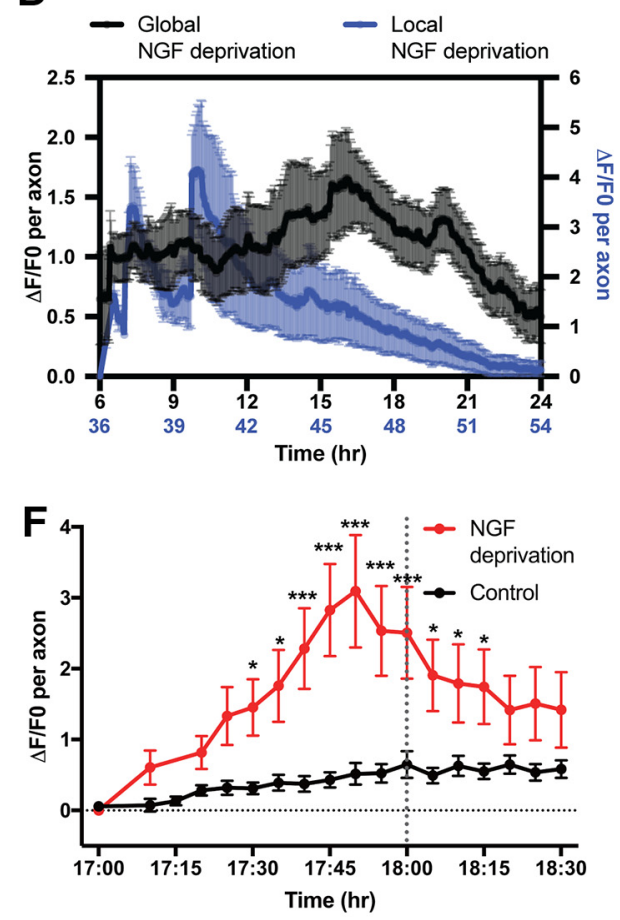

$\mathbf{H}$

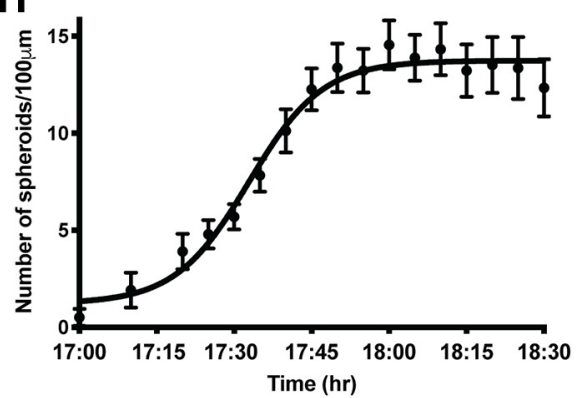

B

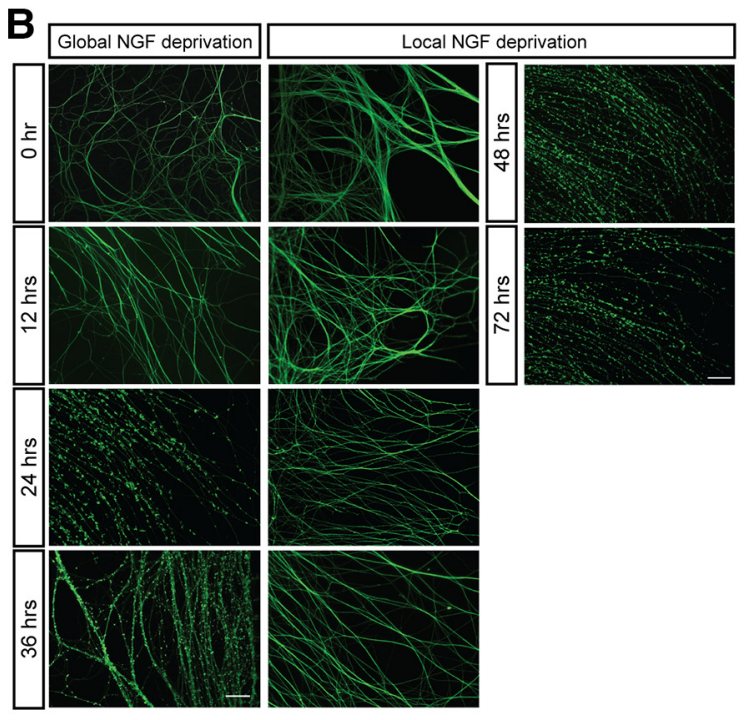

E

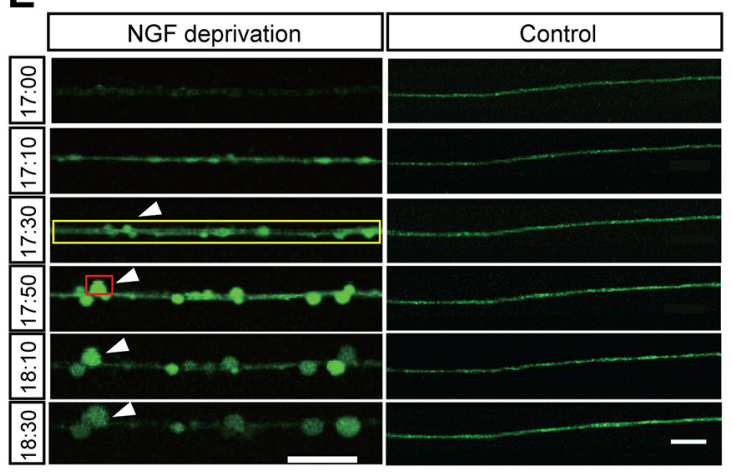

G

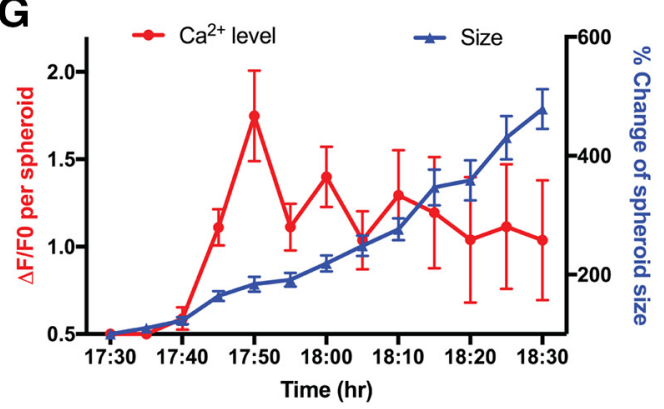

I

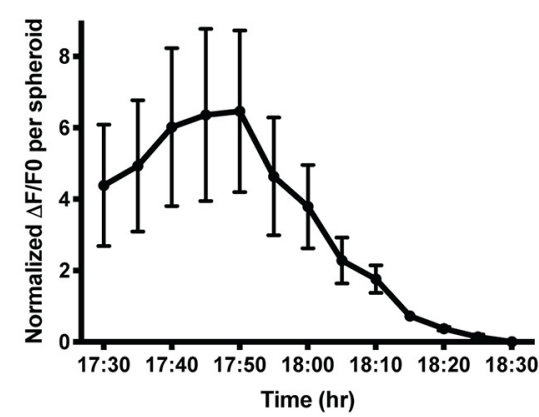

Figure 1. Axoplasmic calcium dynamics and formation of spheroids before catastrophic degeneration in response to NGF deprivation. $A$, Schematic representation of NGF deprivation paradigm in microfluidic devices. Cell bodies (CB) and distal axons (DA) are separated. For global NGF deprivation, sympathetic neurons were maintained in NGF-deficient media containing $1 \mu \mathrm{g} / \mathrm{ml}$ anti-NGF antibody. For local NGF deprivation, sympathetic distal axons were maintained in $80 \mu \mathrm{l}$ per well of NGF-deficient media containing $1 \mu \mathrm{g} / \mathrm{ml}$ anti-NGF antibody. Cell bodies were maintained in 150

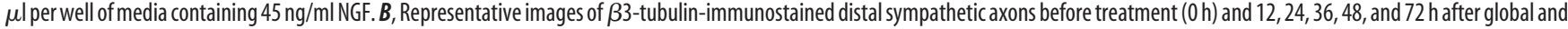
local NGF deprivation. Scale bar, $50 \mu \mathrm{m}$. C, Degeneration time course after NGF deprivation. Latent and catastrophic phases of degeneration are noted. Nonlinear regression curve was drawn according to the Hill equation. $n=3$ for each time point. $\boldsymbol{D}$, Normalized calcium fluorescence change of global (black, left $y$ axis) and local (blue, right $y$ axis) NGF-deprived axons over time. Total number of $n=6$ (global NGF deprivation) and $n=11$ (local NGF deprivation) axons from three independent litters were quantified. $\boldsymbol{E}$, Fluo4-AM calcium (Figure legend continues.) 
A

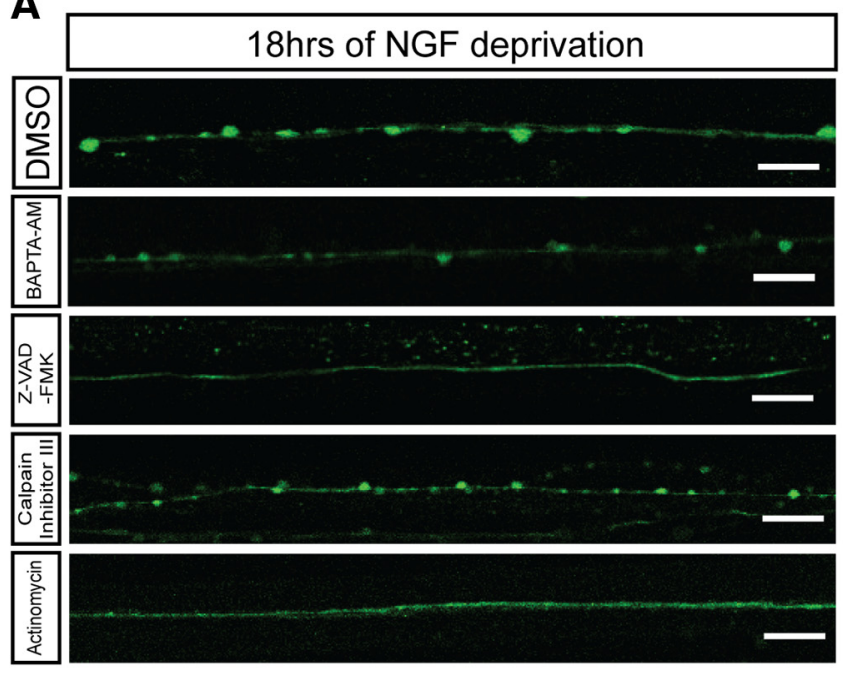

C

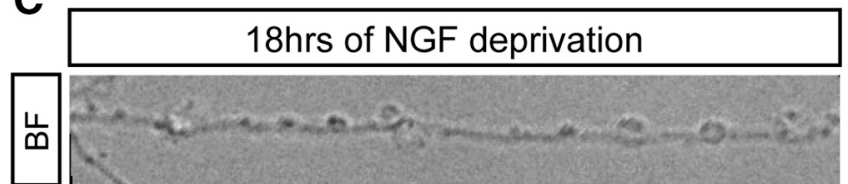

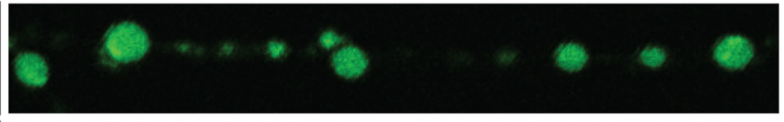
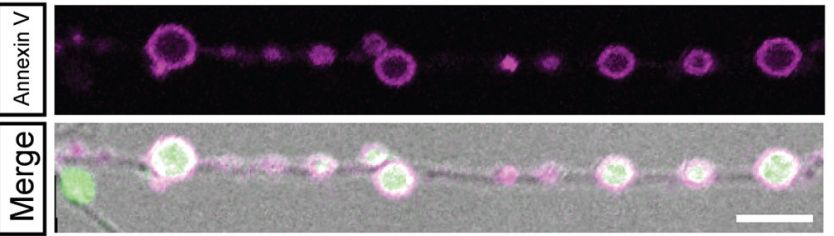

B
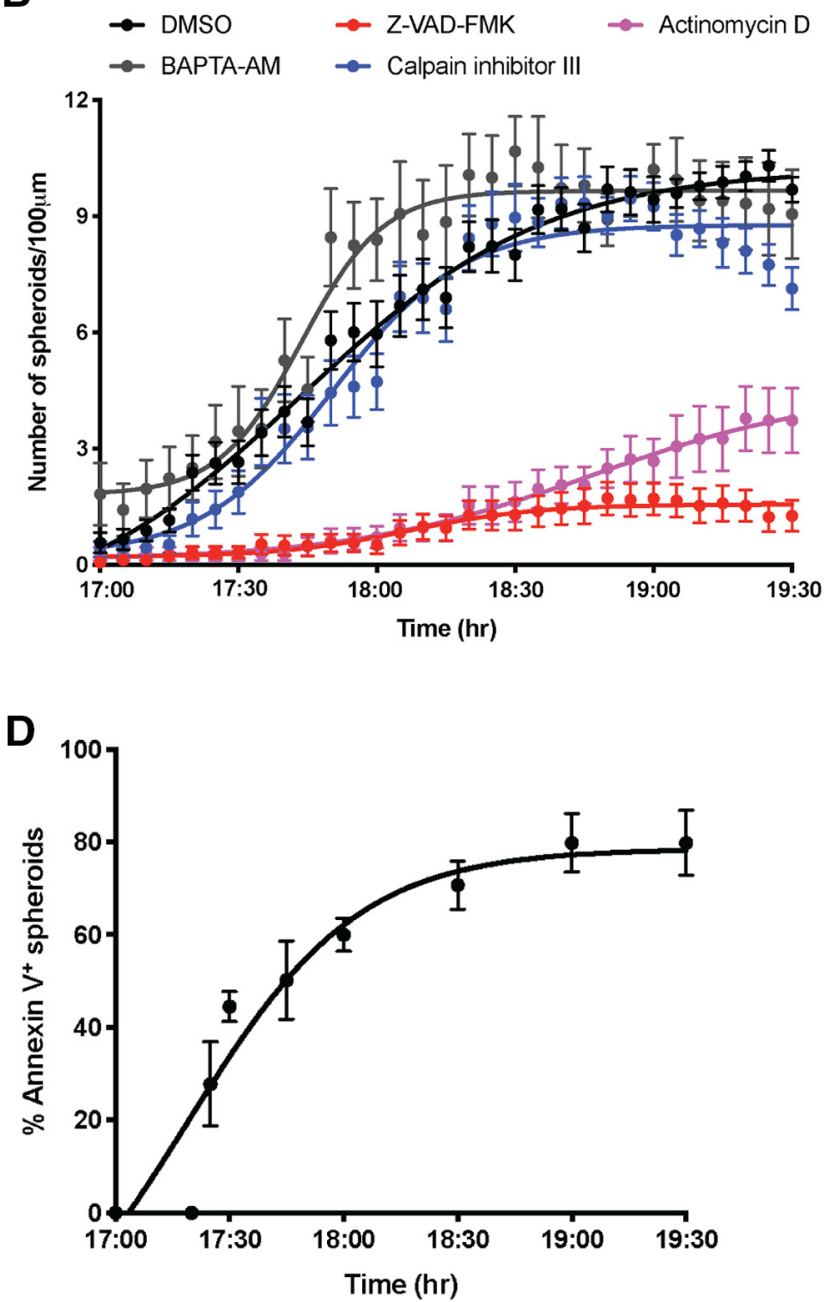

Figure 2. Transcription and caspase activation are required for formation of spheroids. $\boldsymbol{A}, \boldsymbol{B}$, Fluo4-AM calcium imaging $(\boldsymbol{A})$ and quantification of axonal spheroid number per $100 \mu \mathrm{m}$ of sympathetic axons $(\boldsymbol{B})$ at the indicated times after NGF deprivation in the presence of DMSO, $10 \mu \mathrm{M}$ BAPTA-AM, $50 \mu \mathrm{M}$ V-ZAD-FMK, $20 \mu \mathrm{m}$ calpain inhibitor III, and $1 \mu \mathrm{g} / \mathrm{ml}$ actinomycin, respectively. Scale bar, $10 \mu \mathrm{m}$. Nonlinear regression curves were drawn according to the Hill equation. Total number of $n=26$ (DMSO), $n=26$ (BAPTA-AM), $n=25$ (Z-VAD-FMK), $n=20$ (calpain inhibitor III), and $n=17$ (actinomycin) axons from three independent litters were counted. C, Representative images of axonal spheroids after $18 \mathrm{~h}$ of NGF deprivation. Fluo4-AM (green) indicates intra-axonal calcium, and annexin V (magenta) indicates exposure of PS on the outer leaflet on the spheroid membrane. Scale bar, $5 \mu \mathrm{m}$. D, Quantification of the percentage of fluorescent annexin V-positive spheroids after 17-19.5 h of NGF deprivation. Total number of $n=15$ axons from three independent litters were counted. Data are mean \pm SEM.

$\leftarrow$

(Figure legend continued.) imaging of sympathetic axons at the indicated times after global NGF deprivation. For the "NGF deprivation" condition, neurons were globally deprived of NGF for $17 \mathrm{~h}$, and then incubated with Flu04-AM for calcium imaging. For the "Control" condition, no NGF deprivation was performed. Yellow box represents individual axon as ROI. Red box represents axonal spheroid as ROI. White arrowheads indicate the formation and growth of spheroid. Scale bar, $10 \mu \mathrm{m}$. F, Calcium fluorescence change of control or NGF-deprived axons over time. Gray vertical dotted line indicates the onset of catastrophic phase (18 $\mathrm{h}$ after NGF deprivation). Black horizontal dotted line indicates the baseline without any calcium change. Total number of $n=8$ (NGF deprivation) and $n=18$ (control) of axons from three independent litters were quantified. G, Calcium fluorescence and size change of axonal spheroid after $17 \mathrm{~h}$ of global NGF deprivation. Total number of $n=18$ axonal spheroids from three independent litters were quantified. $p=0.0452$ (17:30), $p=0.0059$ (17:35), $p<0.0001$ (17:40, 17:45, 17:50, 17:55, 18:00), $p=0.0037$ (18:05), $p=0.0380$ (18:10), $p=0.0293$ (18:15); two-way ANOVA with Sidak's multiple-comparisons test. $\boldsymbol{H}$, Quantification of axonal spheroid number per $100 \mu \mathrm{m}$ of axon at the indicated times after NGF deprivation. Nonlinear regression curve was drawn according to the Hill equation. Total number of $n=11$ axons from three independent litters were counted. I, Quantification of normalized calcium fluorescence of axonal spheroids from 17.5 to $18.5 \mathrm{~h}$ of global NGF deprivation. Individual axonal spheroids were quantified: $n=18$ spheroids from three independent replicates. Data are mean \pm SEM. ${ }^{*} p<0.05,{ }^{* * *} p<0.0001$. changes of NGF-deprived axons by live imaging. We find that axons retain their capacity to form spheroids in the absence of intra-axonal calcium elevation (Fig. $2 A, B$ ). These data indicate that, although intra-axonal calcium flux may correlate with entry into the catastrophic phase of degeneration, it is not required for spheroid formation.

Transcriptional induction of caspase activation is upstream of spheroid formation

Global NGF deprivation initiates apoptotic pathways to drive degeneration of axons and soma (Deckwerth and Johnson, 1993; Geden et al., 2019). Because caspases and calpain have been proposed to be involved in axon degeneration (Simon et al., 2012, 2016; Cusack et al., 2013; Ma et al., 2013; Yang et al., 2013), we next examined the requirement of these proteases in the formation of spheroids after NGF deprivation. Application of the pancaspase inhibitor Z-VAD-FMK, but not calpain inhibitor III, blocked spheroid formation (Fig. 2A). Less than two spheroids per $100 \mu \mathrm{m}$ of axons were observed in NGF-deprived cultures treated with Z-VAD-FMK, while the numbers of spheroids 


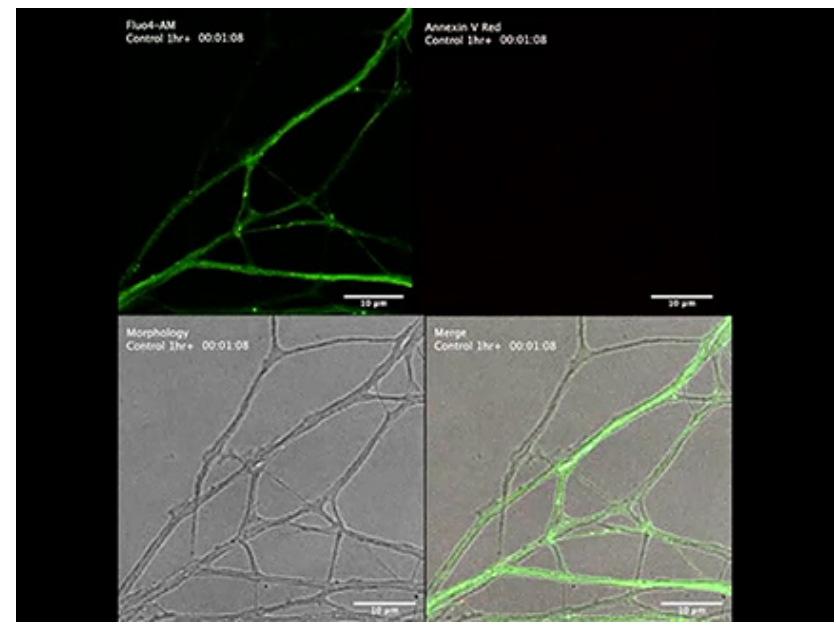

Movie 1. Axoplasmic calcium dynamics without NGF deprivation. Flu04-AM (green) and annexin V (red) live imaging of WT sympathetic axons with NGF. Scale bar, $10 \mu \mathrm{m}$.

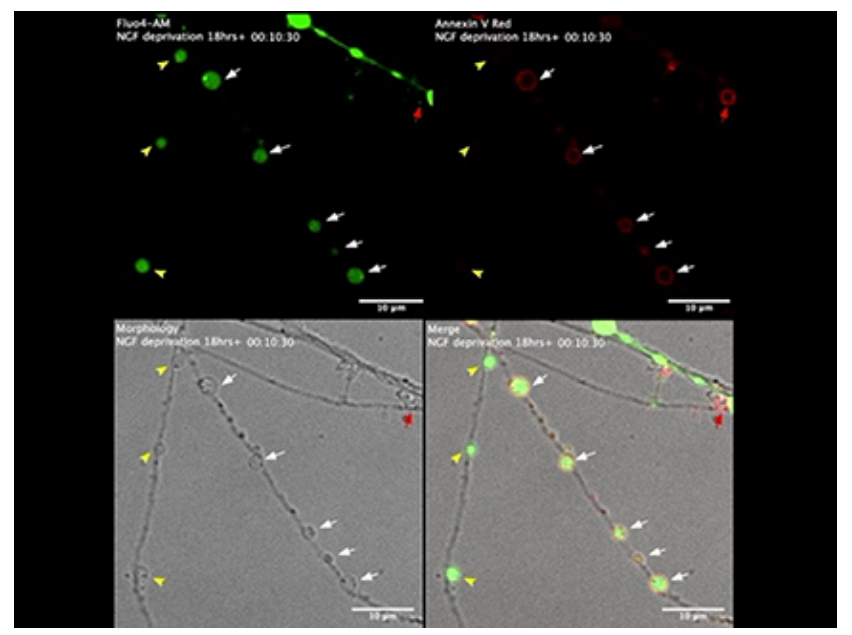

Movie 2. PS flipping of spheroidal membrane with NGF deprivation. Fluo4-AM (green) and annexin V (red) live imaging of WT sympathetic axons after $18 \mathrm{~h}$ of NGF deprivation. White arrows indicate calciumenriched spheroids with PS flipping. Red arrow indicates ruptured spheroids. Yellow arrowheads indicate calcium-enriched spheroids without membrane disruption. Scale bar, $10 \mu \mathrm{m}$. reached $10.2 \pm 0.4$ and $8.8 \pm 0.2$ per $100 \mu \mathrm{m}$ after $19 \mathrm{~h}$ of NGF deprivation in the DMSO and calpain inhibitor III treatments, respectively (Fig. $2 B$ ). Together, these data indicate that caspase activation is upstream of spheroid formation occurring at the transition between latent and catastrophic phases.

It has been suggested that transcriptional upregulation of proapoptotic proteins (e.g., PUMA) are required for axon degeneration after trophic withdrawal (Maor-Nof et al., 2016; Simon et al., 2016). To determine whether inhibition of early prodegeneration transcriptional events could delay spheroid formation, we treated cell bodies with a transcription inhibitor, actinomycin D, at the same time cells were deprived of NGF and examined spheroid formation between 17 and $19.5 \mathrm{~h}$ after trophic withdrawal. Interestingly, actinomycin D significantly diminished spheroid formation compared with the DMSO control (Fig. 2A,B). Based on previous reports, we speculate that a transcriptional program induced by NGF withdrawal is permissive for the activation of caspase pathways, which in turn promotes spheroid formation (Maor-Nof et al., 2016; Simon et al., 2016).

Once cells become apoptotic, plasma membrane PS asymmetry is lost and membranes undergo blebbing. Importantly, PS enrichment on the outer leaflet of the plasma membrane is read as an "eat me" signal for phagocytes to aid apoptotic cell recognition and clearance (Poon et al., 2014; Zhang et al., 2018). After NGF deprivation, the formation of axonal spheroids was detected by live imaging. We next assessed PS exposure on the extracellular surface of axonal spheroids by annexin $\mathrm{V}$ staining, which fluoresces upon binding to PS (Fig. 2C; Movies 1, 2). After $18 \mathrm{~h}$ of NGF deprivation, $\sim 60 \%$ of spheroids, but not the rest of the axon, are annexin V-positive (Fig. 2D), suggesting PS flipping to the outer leaflet on the spheroid membrane.

\section{Axonal spheroids develop membrane ruptures after NGF deprivation}

Whereas annexin V staining is consistent with PS flipping to the outer leaflet of the plasma membrane, it is also formally possible that the membrane integrity of growing spheroids is disrupted, allowing access of the $45 \mathrm{kDa}$ annexin $\mathrm{V}$ protein to the inner leaflet of the plasma membrane. To test this, we bathed control or
NGF-deprived axons in neutral fluorescent dextrans of different sizes $(3,10,70 \mathrm{kDa})$. If there were any ruptures on the membrane after NGF deprivation, the dextran would immediately diffuse to the axoplasm (Fig. 3A). The exclusion of dextran was maintained until $17 \mathrm{~h} 40 \mathrm{~min}$ after NGF deprivation; however, by $17 \mathrm{~h} 50 \mathrm{~min}$, the axoplasm began to fill with $3 \mathrm{kDa}$ fluorescent dextran (Fig. $3 B$; Movies 3, 5). The fraction of labeled spheroids decreases with increasing size of fluorescent dextran, and no significant spheroidal uptake was observed with $70 \mathrm{kDa}$ dextran (Fig. 3D), indicating that ruptures occur on a nanoscale and are permeable to molecules $\leq 10 \mathrm{kDa}$. Moreover, we observed nonpunctate dextran positivity of spheroids simultaneously as Fluo4-AM dye was lost (Fig. 3C), consistent with membrane rupture. We do observe some spheroids that have punctate dextran labeling, consistent with micropinocytosis; however, the events that we consider rupture are quite distinct and involve rapid and complete filling of the spheroid (Movie 4). If the labeling of annexin $\mathrm{V}$ on spheroids was due to entry of the dye through membrane rupture, the number of spheroids filled with dextran of similar or smaller sizes should be no less than the number of annexin $\mathrm{V}$-positive spheroids. However, only $6.5 \pm 3.1 \%$ of $10 \mathrm{kDa}$ dextran-positive spheroids were observed after $18 \mathrm{~h}$ of NGF deprivation, significantly $<45 \mathrm{kDa}$ annexin $\mathrm{V}$ labeled spheroids (Figs. 2D, 3C), suggesting that the flipping of PS occurs before the entry of dextran or membrane rupture.

\section{Rupture of axonal spheroids disrupts the electrochemical gradient and allows expulsion of axoplasmic material} Just as membrane rupture allows free diffusion of molecules $\leq 10$ $\mathrm{kDa}$ to enter spheroids, we predicted that these ruptures would allow small molecules to freely diffuse out of spheroids. Indeed, once spheroids reach $\sim 400 \%$ of their original size, we observe a diminution of calcium signal, which we speculate is a function of diffusion of Fluo4-AM and calcium out of the spheroid. We sought to use calcium release to the extracellular space as a surrogate to test the hypothesis that small molecules may be released after spheroid rupture. We bathed axons in microfluidic devices in $100 \mu \mathrm{l}$ of calcium-free media and measured extracellular calcium before and after spheroid formation using a Fluo4 spectro- 
A

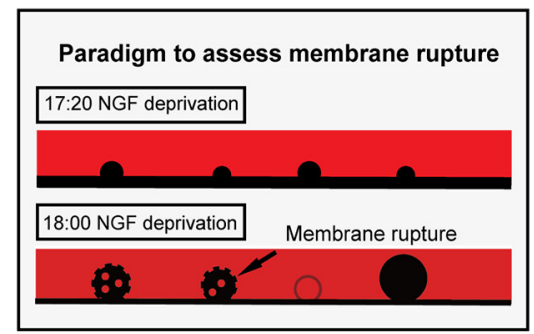

C

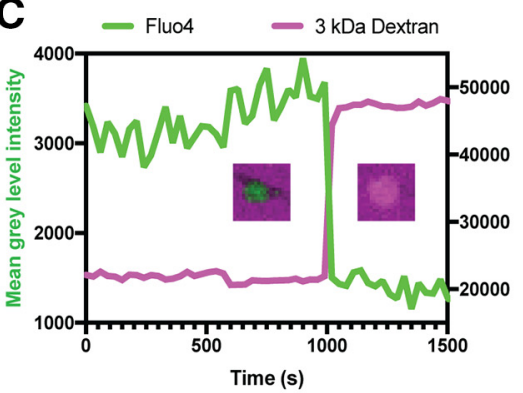

E

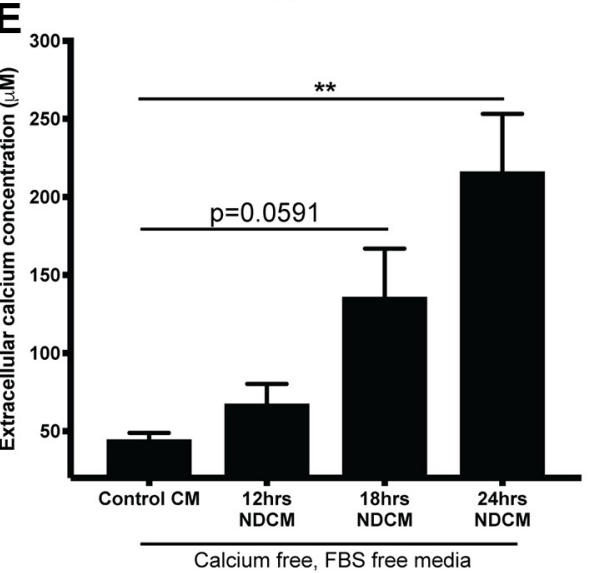

H

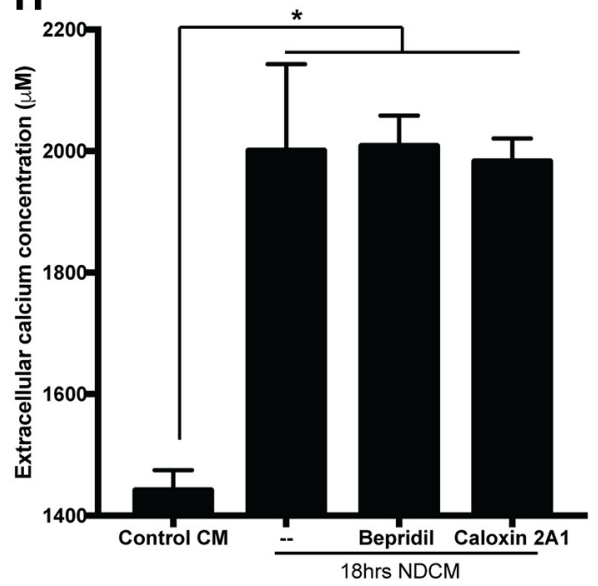

B
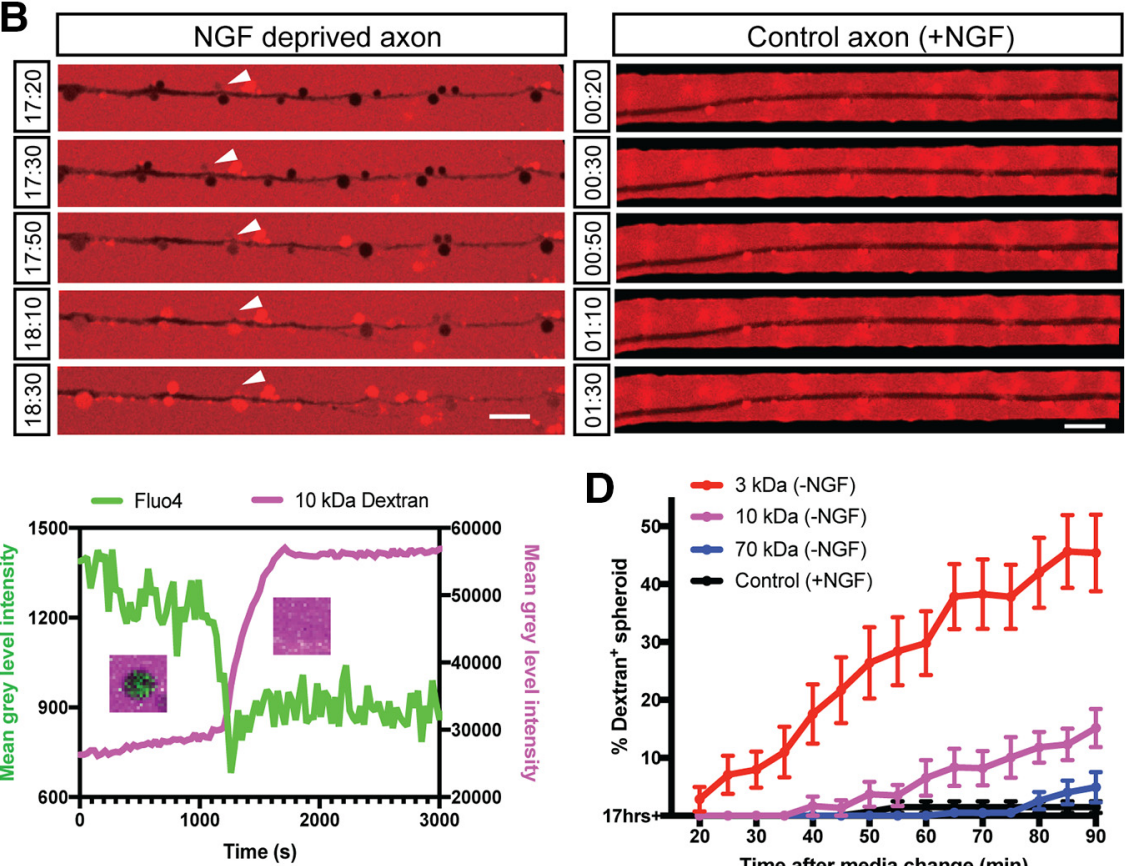

F

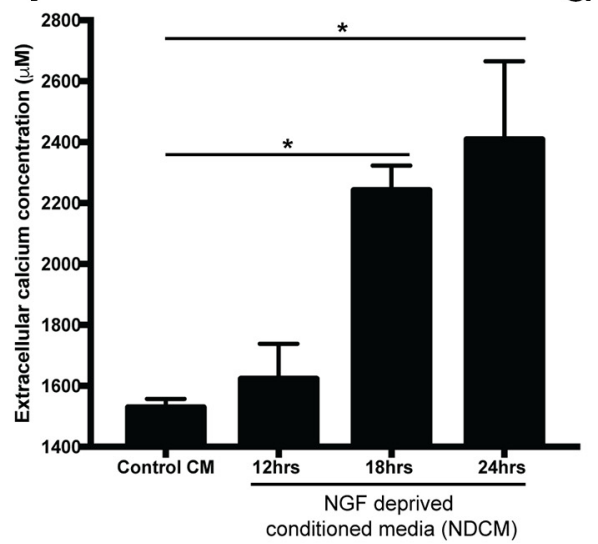

D $-3 \mathrm{kDa}(-\mathrm{NGF})$

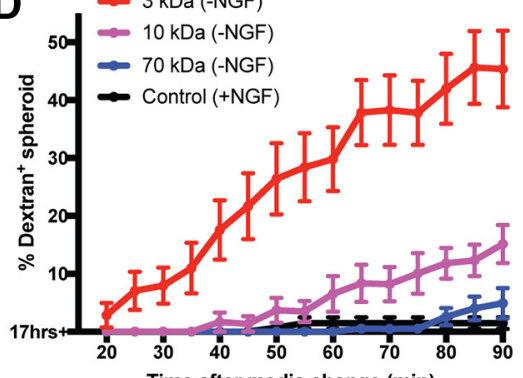

G

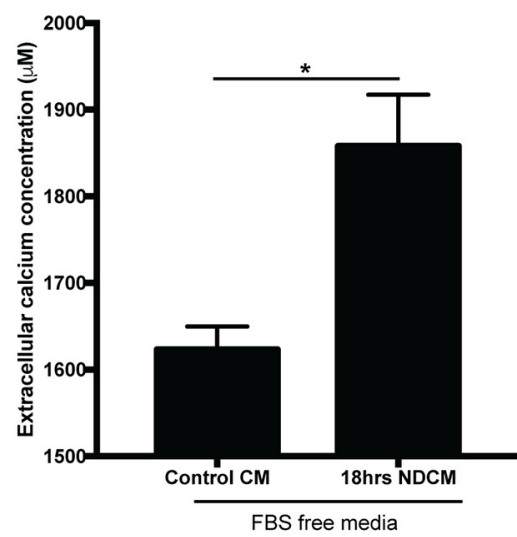

Control

$18 \mathrm{hrs} \mathrm{NDCM}$

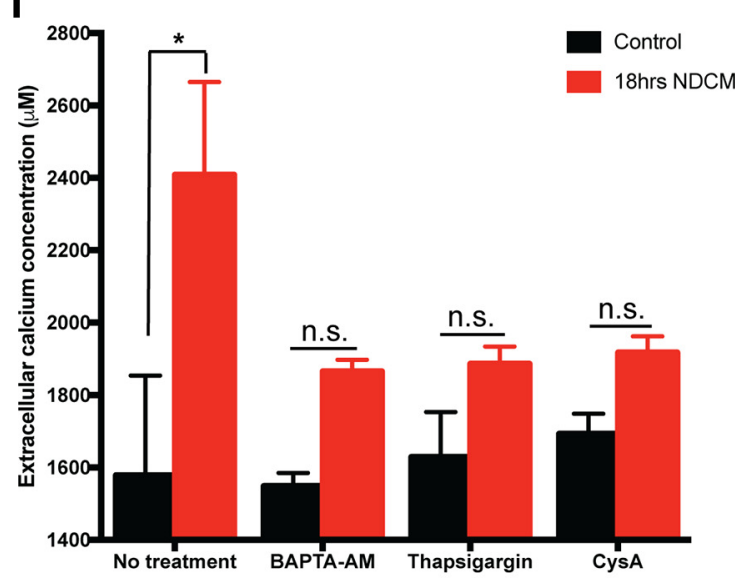

Figure 3. Axonal spheroids develop membrane rupture after NGF deprivation. $A$, Schematic representation of the experimental paradigm to assess membrane rupture model using fluorescent dextran. At $17 \mathrm{~h} 20 \mathrm{~min}$ of NGF deprivation, fluorescent dextran (red) is not taken up by the axon (black, negative space). However, by $18 \mathrm{~h}$ of NGF deprivation, as the plasma membrane loses integrity and ruptures, fluorescent dextran (red) can diffuse into spheroids, turning them red. Spheroids with intact membrane remain black. $\boldsymbol{B}$, Representative images of dextran $3 \mathrm{kDa}$ (red) entry to axonal spheroids (black) from $17 \mathrm{~h} 20 \mathrm{~min}$ to $18 \mathrm{~h} 30 \mathrm{~min}$ of NGF deprivation (left column), and dextran exclusion in untreated axons (right column). White arrowheads indicate that dextran $3 \mathrm{kDa}$ enters axonal spheroids after $18 \mathrm{~h}$ of NGF deprivation. C, Examples of individual spheroidal tracing on NGF-deprived axons labeled with Flu04-AM and bathed in 3 kDa (left) and $10 \mathrm{kDa}$ (right) dextrans, respectively. Right, $y$ axis indicates the mean gray level intensity of dextran fluorescence (magenta) after background subtraction. Left, $y$ axis indicates the mean gray level intensity of Fluo4-AM (green) after background subtraction. Spheroids showing the red/green transition are captured. D, Quantification of the percentages of fluorescent $3 \mathrm{kDa}$ (red), $10 \mathrm{kDa}$ (magenta), and $70 \mathrm{kDa}$ (blue) dextran-positive spheroids 20-90 min after $17 \mathrm{~h}$ NGF deprivation. Black line (control) indicates the percentages of fluorescent $3 \mathrm{kDa}$ dextran-positive (Figure legend continues.) 


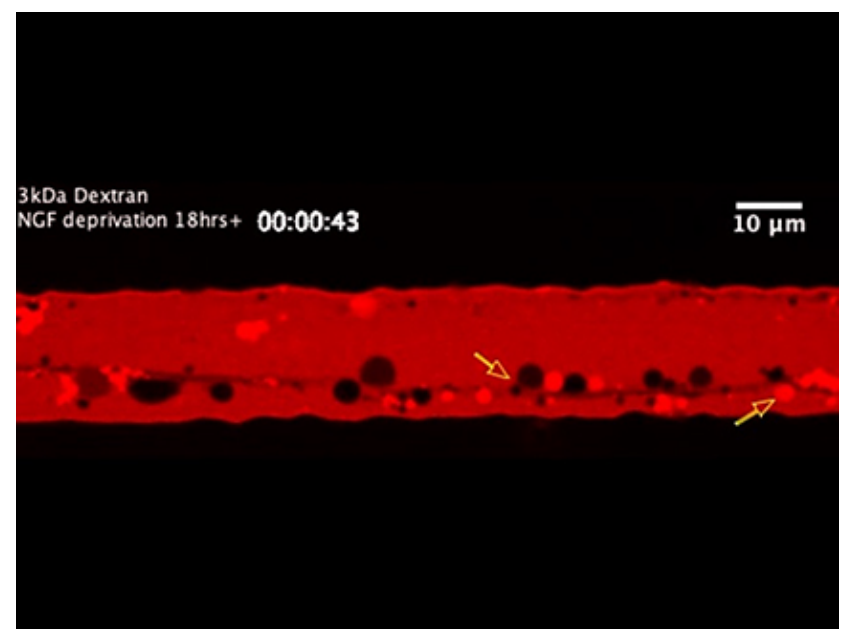

Movie 3. Dextran $3 \mathrm{kDa}$ entry to axonal spheroids after NGF deprivation. Live imaging of dextran $3 \mathrm{kDa}$ (red) entry to axonal spheroids (black) after $18 \mathrm{~h}$ of NGF deprivation. Yellow empty arrows indicate dextran $3 \mathrm{kDa}$ entry to axonal spheroids. Scale bar, $10 \mu \mathrm{m}$.

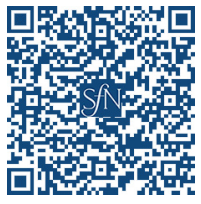

photometric assay. Sympathetic neurons were cultured in media containing FBS and $1.8 \mathrm{~mm}$ calcium, then switched to calciumfree, FBS-free media. We found that $24 \mathrm{~h}$ NDCM contained $\sim 4$ fold higher calcium $(215.50 \pm 37.68 \mu \mathrm{M})$ compared with Control $\mathrm{CM}(43.88 \pm 4.97 \mu \mathrm{M})$ (Fig. $3 E$ ). Additionally, we were also able to observe an increase in extracellular calcium after spheroid rupture when experiments were performed using regular culture media containing FBS and $1.8 \mathrm{~mm}$ calcium. We found that, at $18 \mathrm{~h}$, NDCM displayed a $\sim 50 \%$ increase in calcium $(2.24 \pm 0.08 \mathrm{~mm})$ over Control CM $(1.53 \pm 0.03 \mathrm{~mm})$ (Fig. $3 F)$. To rule out the

$\leftarrow$

(Figure legend continued.) spheroids in the presence of NGF. Total number of $n=15(3 \mathrm{kDa})$, $n=15(10 \mathrm{kDa}), n=12(70 \mathrm{kDa})$, and $n=9$ (control) axons from three independent litters were counted. $\boldsymbol{E}$, Measurement of extracellular calcium expelled from axons into calcium-free, FBS-free media. All axons were grown in regular DMEM and then switched to calcium-free, FBS-free media before NGF deprivation. In the Control CM group, media were collected from axons grown in the presence of NGF. In NDCM groups, media were collected at 12, 18, and $24 \mathrm{~h}$ after NGF deprivation. Values were analyzed from $n=7$ (Control CM), $n=5(12 \mathrm{~h} \mathrm{NDCM}), n=$ $6(18 \mathrm{~h} \mathrm{NDCM})$, and $n=7$ (24h NDCM) independent replicates. Compared with Control CM, $p=$ 0.0591 for $18 \mathrm{~h} \mathrm{NDCM}, p=0.0003$ for $24 \mathrm{~h}$ NDCM (one-way ANOVA with Dunnett's multiplecomparisons test). $\boldsymbol{F}$, Measurement of extracellular calcium concentration of untreated and NGF-deprived conditioned media. Values were analyzed from $n=7$ (Control CM), $n=4$ (12 h NDCM), $n=6$ (18 h NDCM), and $n=8$ (24 h NDCM) independent replicates. Compared with Control CM, $p=0.0227$ for $18 \mathrm{~h}$ NDCM, $p=0.0026$ for $24 \mathrm{~h}$ NDCM (one-way ANOVA with Dunnett's multiple-comparisons test). G, Measurement of extracellular calcium extruded from axons into FBS-free, IS21 supplemented DMEM with or without $18 \mathrm{~h}$ of NGF deprivation. All axons were grown in FBS-free, IS21 supplemented media before NGF deprivation. $n=8$ (Control CM) and $n=3$ (18 h NDCM) independent replicates ( $p=0.0022$, unpaired $t$ test). $\boldsymbol{H}$, Measurement of extracellular calcium concentrations in Control CM and $18 \mathrm{~h}$ NDCM in the absence and presence of NCX blocker $10 \mu \mathrm{M}$ Bepridril or PMCA blocker $0.5 \mathrm{~mm}$ Caloxin 2A1. $n=$ 4 for Control CM ( $p=0.0038) ; n=4$ for 18 h NDCM $) ;-(p=0.0058) ; n=3$ for 18 h NDCM, Bepridril ( $p=0.0079$ ); $n=3$ for 18 h NDCM, Caloxin 2A1 (one-way ANOVA with Tukey's multiple-comparisons test). I, Measurement of extracellular calcium concentration of untreated and NGF-deprived conditioned media in the presence and absence of intracellular calcium chelator BAPTA-AM (10 $\mu \mathrm{m}, 1 \mathrm{~h}$ incubation before NGF deprivation), SERCA inhibitor thapsigargin (100 nm, overnight treatment before NGF deprivation), and mitochondrial mPTP blocker cyclosporin A (20 $\mu \mathrm{M}, 1 \mathrm{~h}$ treatment before NGF deprivation). $n=3$ for each group. $p=0.0375$ for No treatment; $p=0.7952$ for BAPTA-AM; $p=0.8897$ for thapsigargin; $p=0.9863$ for CysA (two-way ANOVA with Sidak's multiple-comparisons test). Data are mean $\pm \mathrm{SEM} .{ }^{*} p<0.05$, ${ }^{* *} p<0.001$. Scale bar, $10 \mu \mathrm{m}$.

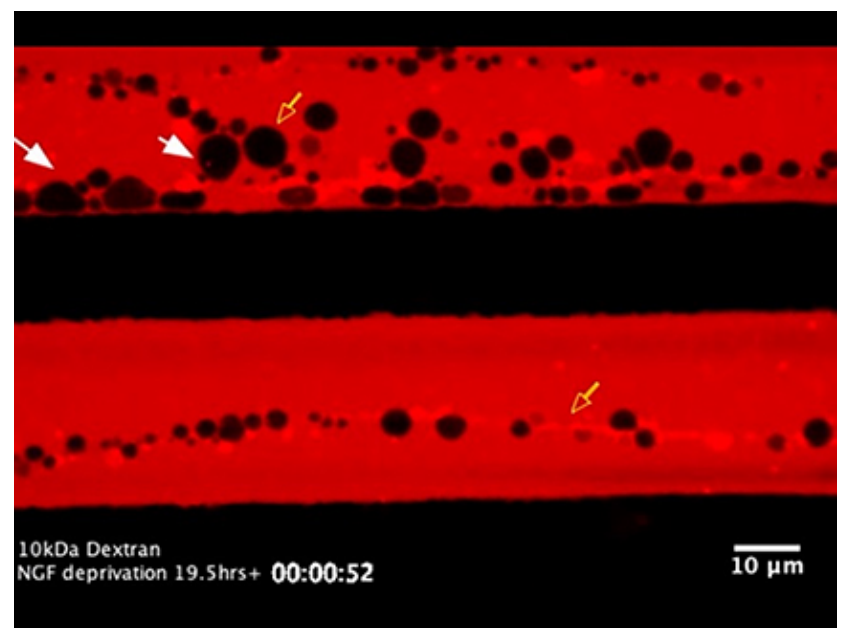

Movie 4. Dextran $10 \mathrm{kDa}$ entry to axonal spheroids after NGF deprivation. Live imaging of dextran $10 \mathrm{kDa}$ (red) entry to axonal spheroids (black) after $19.5 \mathrm{~h}$ of NGF deprivation. Yellow empty arrows indicate that dextran $10 \mathrm{kDa}$ entry to axonal spheroids. White filled arrows indicate spheroids detaching from the axon. Some spheroids display punctate labeling consistent with macropinocytosis before filling, which is consistent with membrane rupture. Scale bar, $10 \mu \mathrm{m}$.

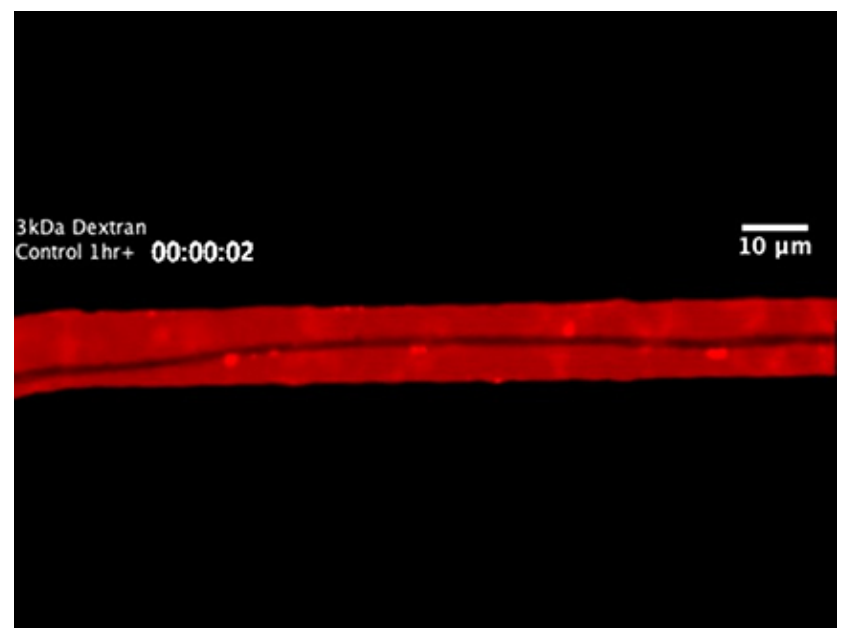

Movie 5. Dextran $3 \mathrm{kDa}$ exclusion of axons without NGF deprivation. Live imaging of dextran $3 \mathrm{kDa}$ (red) exclusion of sympathetic axons in the presence of NGF. Scale bar, $10 \mu \mathrm{m}$.

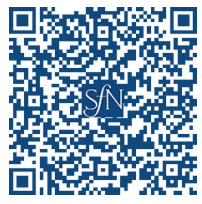

effect of FBS in regular culture media before calcium measurements, neurons were cultured in FBS-free, IS21-supplemented DMEM media. Calcium level in $18 \mathrm{~h}$ NDCM $(1858.08 \pm 59.23$ $\mu \mathrm{M})$ was significantly higher than calcium concentration in Control CM (1623.26 $\pm 26.66 \mu \mathrm{M})$ (Fig. $3 G)$, suggesting that this calcium release occurred regardless of the presence or absence of FBS in the media.

Beyond membrane rupture, it is formally possible that calcium release could be in part due to enhanced permeability of plasma membrane $\mathrm{Ca}^{2+}$ ATPase (PMCA) and/or reversal $\mathrm{Na}^{+} /$ $\mathrm{Ca}^{2+}$ exchanger (NCX) (Bano et al., 2007; Brini and Carafoli, 2011). To test this possibility, we treated NGF-deprived axons with PMCA inhibitor caloxin 2A1 or NCX inhibitor bepridil to test their ability to block elevation of extracellular calcium concentration. Axons deprived of NGF for $18 \mathrm{~h}$ and treated with 

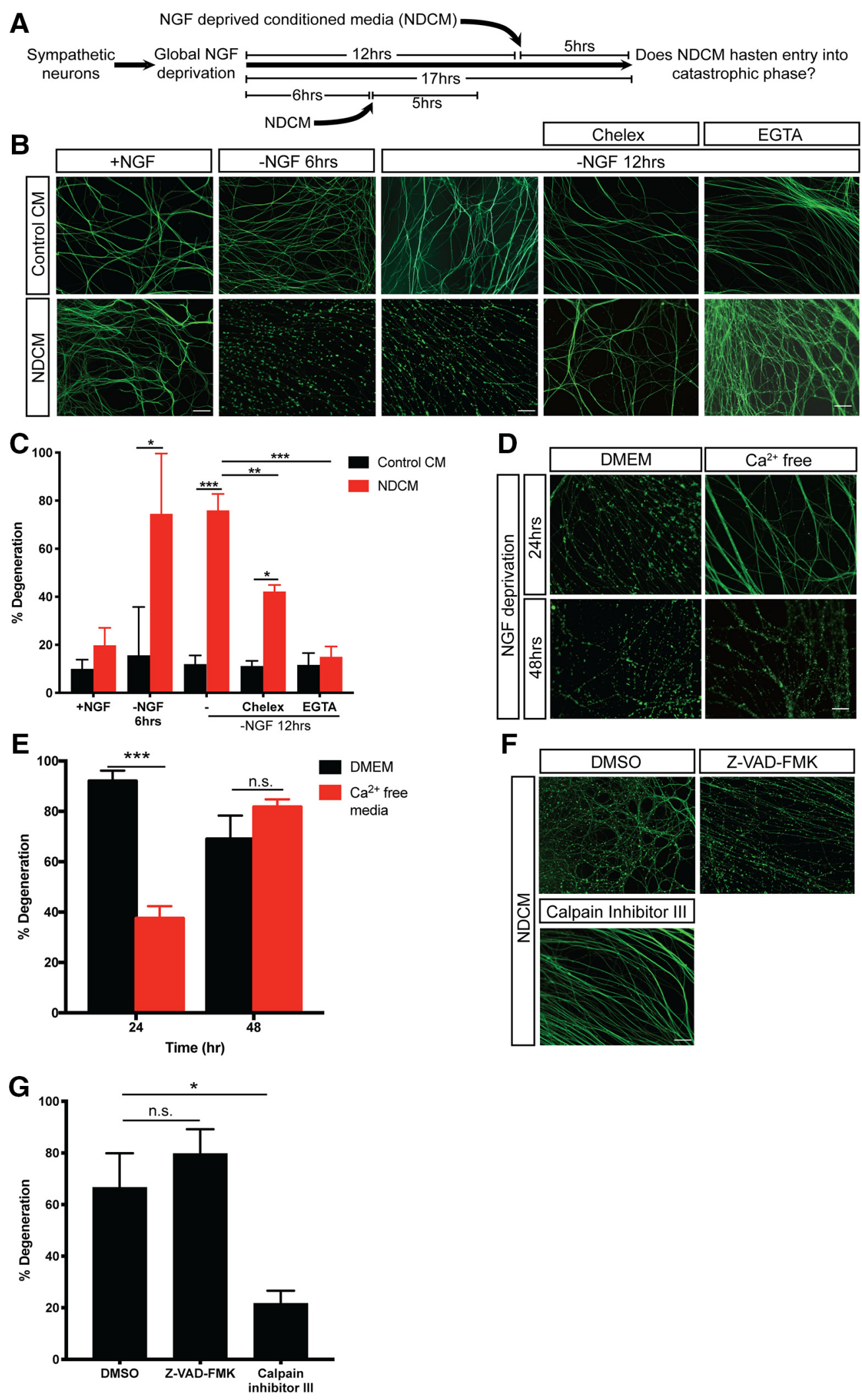

Figure 4. Calcium and calpain activation are required for NDCM-induced catastrophic axon degeneration. $A$, Conditioned media degeneration paradigm. WT sympathetic neurons were globally deprived of NGF for 6 or $12 \mathrm{~h}$ followed by addition of conditioned media to the axons for $5 \mathrm{~h}$. NDCM was collected from degenerated axons after $24 \mathrm{~h}$ of NGF deprivation. $B, C$, Representative images $(B)$ and quantification $(\boldsymbol{C})$ of $\beta 3$-tubulin-immunostained distal sympathetic axons after treatment with Control CM and NDCM for $5 \mathrm{~h}$ in the presence and absence of NGF, Chelex beads, and EGTA $(6 \mathrm{~mm}) . n=4$ or more for each group. For each repeat, at least 100 axons were scored for degeneration. Compared with Control CM, $p=0.0212$ for - NGF $6 \mathrm{~h}, \mathrm{NDCM} ; p<0.0001$ for $-\mathrm{NGF} 12 \mathrm{~h}$, NDCM; $p=0.0021$ for -NGF $12 \mathrm{~h}$, Chelex, NDCM. Compared with -NGF $12 \mathrm{~h}$, NDCM, $p=0.0002$ for -NGF $12 \mathrm{~h}$, Chelex, NDCM; $p<0.0001$ for - NGF $12 \mathrm{~h}$, EGTA, NDCM (two-way ANOVA with Sidak's multiple-comparisons test). $\boldsymbol{D}, \boldsymbol{E}$, Representative images ( $\boldsymbol{D}$ ) and quantification $(\boldsymbol{E})$ of $\beta 3$-tubulin-immunostained distal sympathetic axons after 24 and $48 \mathrm{~h}$ of $\mathrm{NGF}$ deprivation in media with calcium (DMEM) and calcium-free media. Axons were cultured in regular media (DMEM) and then switched to calcium-free media at the time of NGF deprivation. (Figure legend continues.) 
caloxin $2 \mathrm{~A} 1$ or bepridil retained their ability to release calcium to the extracellular space (Fig. $3 H$ ). Thus, spheroidal calcium is released to extracellular space independent of PMCA or NCX.

The observation that calcium in the media is elevated after membrane rupture is curious because the calcium concentration outside of the cell ( $1.8 \mathrm{~mm})$ is known to be much higher than in the axoplasm (100 nM) (LaFerla, 2002; Clapham, 2007). How the axoplasm would have sufficient quantities of free calcium to appreciably elevate calcium levels in the media is unclear. To gain insight into this, we sought to determine the source of expelled intra-axonal calcium. We began by chelating all intracellular calcium with $10 \mu \mathrm{M}$ BAPTA-AM added $1 \mathrm{~h}$ before NGF deprivation, which prevented calcium release to the extracellular space $18 \mathrm{~h}$ after trophic deprivation (Fig. 3I). Intracellular calcium is buffered and stored by a contiguous network of ER and mitochondria, and calcium flux is thought to contribute to axon degeneration (Mattson, 2007; Villegas et al., 2014). Depletion of ER or mitochondria calcium, by treating neurons with $100 \mathrm{~nm}$ thapsigargin or $20 \mu \mathrm{M}$ cyclosporine A for $12 \mathrm{~h}$ before NGF deprivation, also blocked calcium increase in the extracellular space (Fig. $3 I$ ). These results suggest that the elevated extracellular calcium comes from intracellular calcium stores.

We expect that, in physiological scenarios, membrane rupture would also allow disruption of the calcium electrochemical gradient between the inside and outside of the cell. In this way, elevated calcium level in the extracellular space may represent a surrogate for the release of other small molecules as well as a sustained elevation of intracellular calcium, which may lead to activation of calpain. Importantly, we are unable to observe sustained elevation of axoplasmic calcium after rupture (Fig. 1D) because the calcium indicator, Fluo4-AM, used in the above experiments would also diffuse out of the axon.

\section{Expelled axoplasmic prodegenerative molecules hasten entry of axons into catastrophic phase}

We speculated that contents released from ruptured spheroids may induce entry into the catastrophic phase of degeneration. To examine this, we collected media surrounding distal axons after $24 \mathrm{~h}$ of NGF deprivation (24 h NDCM) and incubated intact NGF-deprived axons for $5 \mathrm{~h}$ in $24 \mathrm{~h}$ NDCM (Fig. 4A). Importantly, in this paradigm, the total time that recipient axons are incubated without NGF are 11 and $17 \mathrm{~h}$ for "-NGF $6 \mathrm{~h}$ " and “-NGF 12 h" groups, respectively, before stereotypical morphological changes associated with degeneration. Neurons treated with Control CM (from untreated axons at time 0 of NGF deprivation) displayed minimal degeneration, which is consistent with the kinetics of the trophic deprivation time course presented in Figure $1 C$. However, we found that intact axons treated with NDCM displayed $74.5 \pm 25.1 \%$ and $76.0 \pm 6.8 \%$ degeneration at 11 and 17 h time points, respectively (Fig. $4 B, C$ ). Additionally, in the presence of NGF, NDCM failed to promote degeneration in $5 \mathrm{~h}$

\section{$\leftarrow$}

(Figure legend continued.) $n=3$ for each group. For each repeat, at least 100 axons were scored for degeneration. $p<0.0001$ for $24 \mathrm{~h}, p=0.4766$ for $48 \mathrm{~h}$ (two-way ANOVA with Sidak's multiple-comparisons test). $\boldsymbol{F}, \boldsymbol{G}$, Representative images $(\boldsymbol{F})$ and quantification $(\boldsymbol{G})$ of $\beta 3$ tubulin-immunostained distal sympathetic axons after treatment with NDCM for $5 \mathrm{~h}$ in the presence of DMSO, $50 \mu \mathrm{m}$ Z-VAD-FMK, and $20 \mu \mathrm{m}$ calpain inhibitor III, respectively. All cultures were globally deprived of NGF for $12 \mathrm{~h}$ before NDCM incubation. Compared with DMSO $(n=7)$, $p=0.5328, n=9$ for Z-VAD-FMK; $p=0.0080, n=8$ for calpain inhibitor III (one-way ANOVA with Dunnett's multiple-comparisons test). Data are mean \pm SEM. ${ }^{*} p<0.05,{ }^{* *} p<0.001$, ${ }^{* * *} p<0.0001$. Scale bar, $50 \mu \mathrm{m}$. of incubation (Fig. $4 B, C$ ), indicating that loss of NGF prosurvival signal is necessary to drive catastrophic axonal degeneration.

\section{Extracellular calcium and calpain activation are required for} entry into the catastrophic phase of degeneration

Small prodegenerative molecules may be released to extracellular space and reenter axoplasma via membrane rupture to promote degeneration. If sustained elevation of intracellular calcium is required for axons to trigger catastrophic degeneration, we would expect that blocking the prodegenerative-positive feedback step by depleting extracellular calcium would delay catastrophic degeneration. To this end, we performed trophic deprivation using calcium-free DMEM. NGF-deprived WT axons maintained in DMEM with $1.85 \mathrm{mM}$ calcium showed classic degenerative hallmarks, such as beading, blebbing, and fragmentation by $24 \mathrm{~h}$ (Fig. $4 D)$. Remarkably, when neurons were grown in calcium-free media, their rate of degeneration slowed. After $24 \mathrm{~h}$ of NGF deprivation, only $38 \%$ of axons were degenerated in calcium-free media; however, maximal degeneration was observed $48 \mathrm{~h}$ after NGF deprivation (Fig. 4D,E). Moreover, both chelex resin (which sequesters all divalent cations) and EGTA (which depletes calcium from NDCM) suppressed the ability of NDCM to promote degeneration in recipient axons (Fig. $4 B, C$ ). Thus, extracellular calcium is required to promote catastrophic degeneration in trophically deprived sympathetic axons. This is consistent with observations in trophically deprived sensory neurons and enucleated sympathetic neurons (George et al., 1995; Johnstone et al., 2019).

To explore the downstream effector of calcium influx during developmental axon degeneration, we applied NDCM to recipient axons in the presence of calpain inhibitor III or Z-VAD-FMK. Interestingly, after $5 \mathrm{~h}$ of incubation, only $21.6 \pm 5.0 \%$ of axons were degenerated in cultures treated with calpain inhibitor III, significantly less than the DMSO group (66.6 $\pm 13.3 \%)$, whereas axons bathed in Z-VAD-FMK displayed $79.7 \pm 9.6 \%$ of degeneration (Fig. $4 F, G$ ). These results indicate that calpain, instead of caspase, acts downstream of spheroid rupture and sustained calcium influx to promote catastrophic degeneration.

\section{p75NTR, but not DR6, regulates the timing of spheroid formation and axoplasmic content expulsion to the extracellular space}

Based on the above results, we have identified three events before catastrophic axon degeneration: (1) an intra-axonal calcium increase; (2) calcium-independent spheroid formation and membrane rupture; and (3) triggering of catastrophic degeneration by NDCM. What are the pathways upstream and downstream of these events? To address this, we examined the role of two TNFR family members, DR6 and p75NTR, which we and others have implicated in axon degeneration following trophic withdrawal (Park et al., 2010; Twohig et al., 2011; Olsen et al., 2014; Gamage et al., 2017).

We first examined whether p75NTR or DR6 acts upstream of spheroid formation and membrane rupture. To this end, we performed intra-axonal calcium imaging in NGF-deprived $D R 6^{-/-}$ and $p 75 \mathrm{NTR}^{-1-}$ sympathetic axons. Both WT and $D R 6^{-1-}$ axons displayed up to a fivefold increase of spheroidal calcium levels; however, $p 75 \mathrm{NTR}^{-/-}$sympathetic axons did not display a significant increase in spheroidal calcium, even after $20 \mathrm{~h} 30 \mathrm{~min}$ of NGF deprivation (Fig. $5 A, B$ ). We next examined the role of p75NTR and DR6 in the accumulation of spheroids and the change in their size as a function of time after NGF deprivation. At $18 \mathrm{~h}$ after NGF deprivation, WT and $D R 6^{-1-}$ neurons dis- 

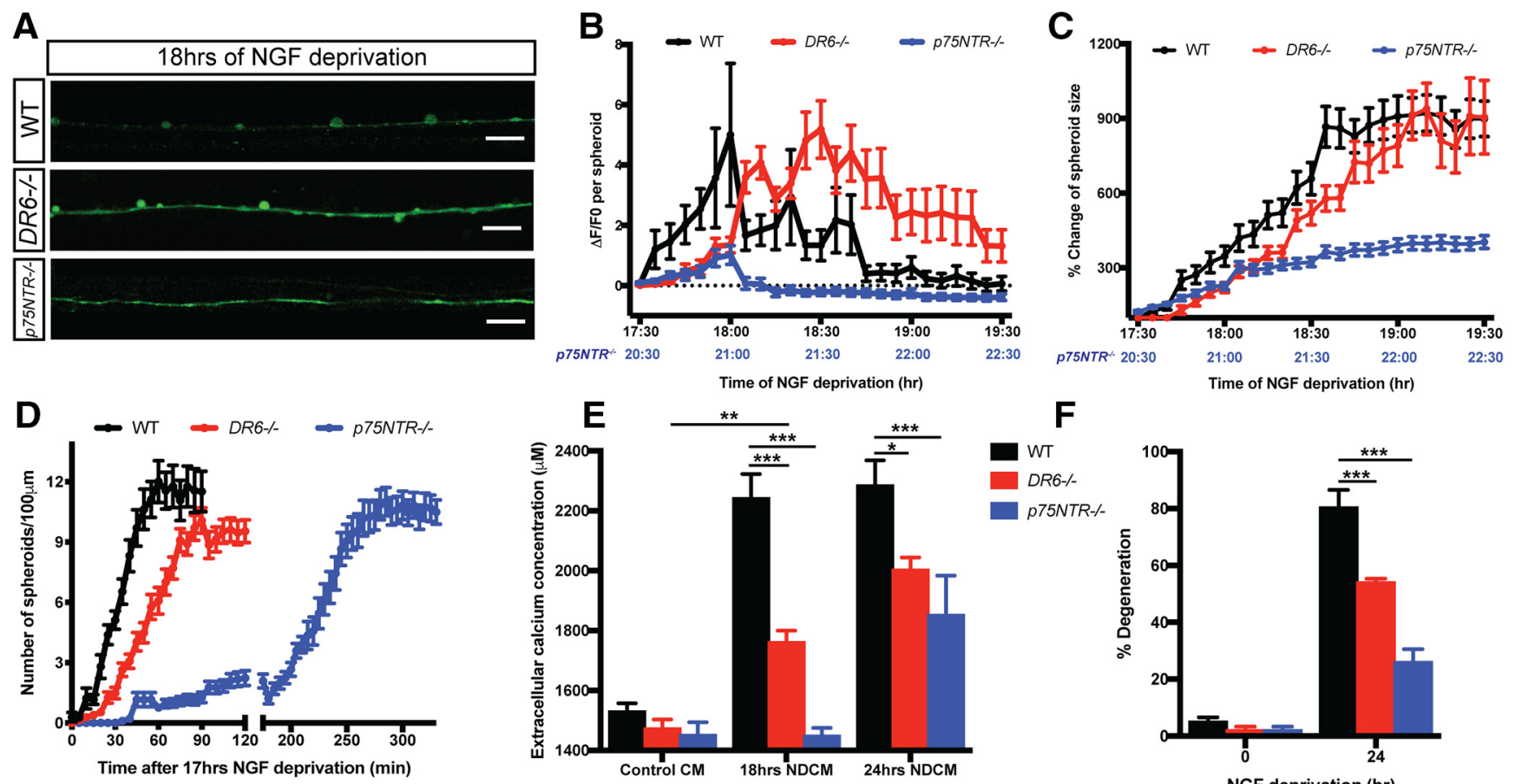

G

Wild-type sympathetic
neurons
Global NGF deprivation

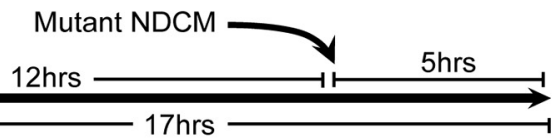

NGF deprivation (hr)

H

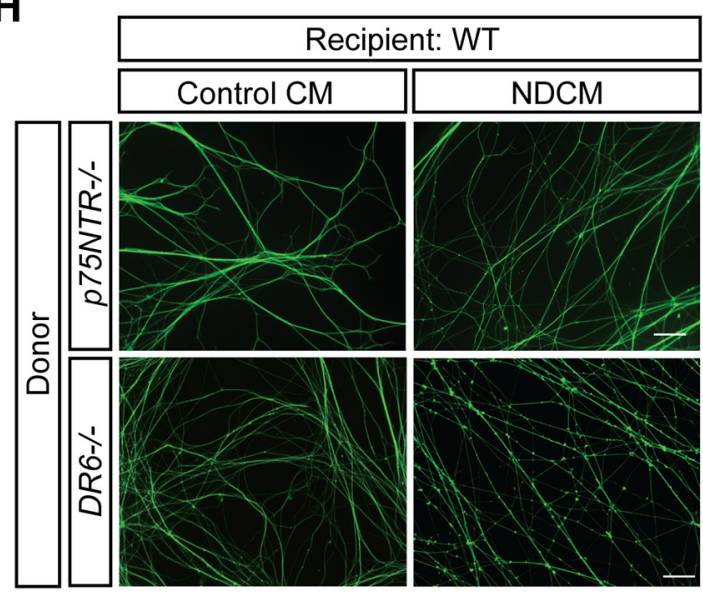

I

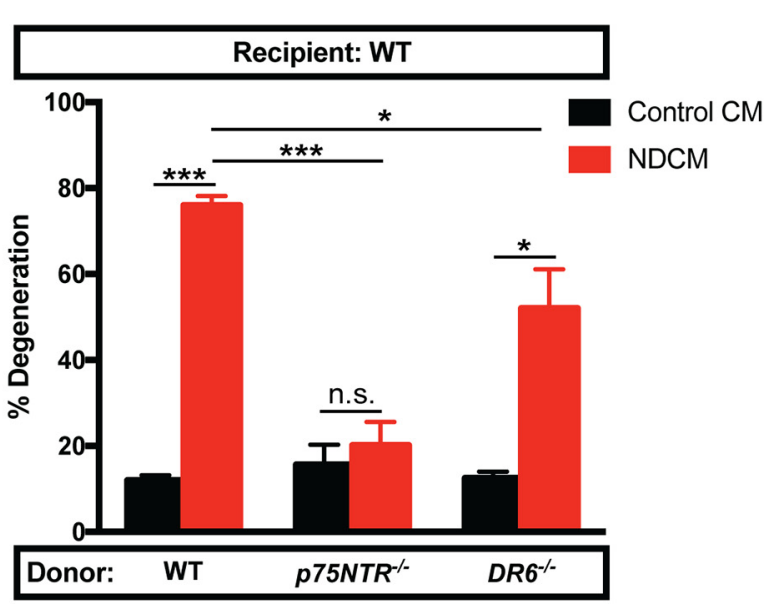

Figure 5. Depletion of p75NTR delays formation of spheroids and prodegenerative molecule exclusion after NGF deprivation. $A$, Flu04-AM calcium imaging of WT, DR6 ${ }^{-/-}$, and $p 75 N T R^{-/-}$ sympathetic axons $18 \mathrm{~h}$ of NGF deprivation. Scale bar, $10 \mu \mathrm{m} . \boldsymbol{B}, \boldsymbol{C}$, Spheroidal calcium fluorescence $(\boldsymbol{B})$ and size change $(\boldsymbol{C})$ of WT, DR6 ${ }^{-1-}$, and $p 75 N T R^{-1-}$ sympathetic axons after indicated time of NGF deprivation. $\boldsymbol{B}$, Horizontal dotted line indicates the baseline without any calcium change. Lower $x$ axis labeled with blue correlates with time of NGF deprivation in $p 75 N^{2} R^{-1-}$ sympathetic axons. Individual axonal spheroids were quantified: $n=32$ (WT), $n=30\left(D R \sigma^{-/-}\right)$, and $n=22\left(p 75 N^{-1-} R^{-}\right.$) spheroids from cultured neurons harvested from three independent litters. $D$, Quantification of axonal spheroid number per $100 \mu \mathrm{m}$ of WT, DR6 ${ }^{-1-}$, and $p 75 \mathrm{NTR}^{-/-}$sympathetic axon at the indicated times after $17 \mathrm{~h}$ of NGF deprivation. Individual axonal spheroids were counted: $n=20(\mathrm{WT}), n=29\left(\left(D R 6^{-1-}\right)\right.$, and $n=22\left(p 75 \mathrm{NTR}^{-1-}\right)$ axons from cultured neurons harvested from three independent litters. $E$, Measurement of extracellular calcium concentration

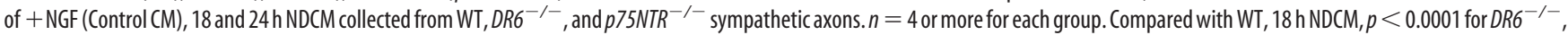
$18 \mathrm{~h} \mathrm{NDCM} ; p<0.0001$ for $p 75 N \mathrm{NR}^{-/-}, 18 \mathrm{~h} \mathrm{NDCM}$. Compared with WT, $24 \mathrm{~h} \mathrm{NDCM}, p=0.0026$ for DR6 ${ }^{-/-}, 24 \mathrm{~h} \mathrm{NDCM} ; p<0.0001$ for $p 75 \mathrm{NTR}^{-/-}, 24 \mathrm{hNDCM}$. Compared with DR6 ${ }^{-/-}$, Control $C M, p=0.0045$ for $D R 6^{-/-}, 18 \mathrm{~h} \mathrm{NDCM}$ (two-way ANOVA with Dunnett's multiple-comparisons test). $F$, Quantification of degeneration of WT, DR6 ${ }^{-1-}$, and $p 75 N R^{-/-}$sympathetic axons with or without $24 \mathrm{~h}$ of NGF deprivation. $n=3$ or more for each group. For each repeat, at least 100 axons were scored for degeneration. Compared with WT, $24 \mathrm{~h}, p<0.0001$ for DR6 ${ }^{-1-}, 24 \mathrm{~h} ; p<$ 0.0001 for $p 75 N^{-1-}, 24 \mathrm{~h}$ (two-way ANOVA with Dunnett's multiple-comparisons test). G, Catastrophic axon degeneration paradigm to test the prodegenerative effect of mutant NDCM. WT sympathetic neurons were globally deprived of NGF for $12 \mathrm{~h}$ followed by addition of conditioned media derived from mutant axons for $5 \mathrm{~h}$. Mutant NDCM was collected from degenerating p75NTR ${ }^{-\prime-}$ or DR6 ${ }^{-/-}$axons $24 \mathrm{~h}$ after NGF deprivation. $\boldsymbol{H}, \boldsymbol{I}$, Representative images $(\boldsymbol{H})$ and quantification $(\boldsymbol{I})$ of WT distal sympathetic axons immunostained for $\beta 3$-tubulin after treatment with Control CM and NDCM collected from $p 75 N T R^{-/-}$and $D R 6^{-/-}$axons for $5 \mathrm{~h}$. Scale bar, $50 \mu \mathrm{m}$. Left two columns represent percentages of degeneration of WT sympathetic axons treated with WT NDCM and Control CM, respectively. Compared with WT, NDCM $(n=10), p<0.0001, n=7$ for $p 75 \mathrm{NTR}^{-/-}$, NDCM; $p=0.0010, n=7$ for DR6 ${ }^{-/-}$, NDCM (two-way ANOVA with Dunnett's multiple-comparisons test). Compared with Control CM, $p<0.0001$ for WT, NDCM; $p=0.8980$ for $p 75 N_{T R}{ }^{-/-}$, NDCM; $p=0.0014$ DR6 $^{-/-}$, NDCM (two-way ANOVA with Sidak's multiplecomparisons test). Data are mean \pm SEM. ${ }^{*} p<0.05,{ }^{* *} p<0.001,{ }^{* * *} p<0.0001$. 

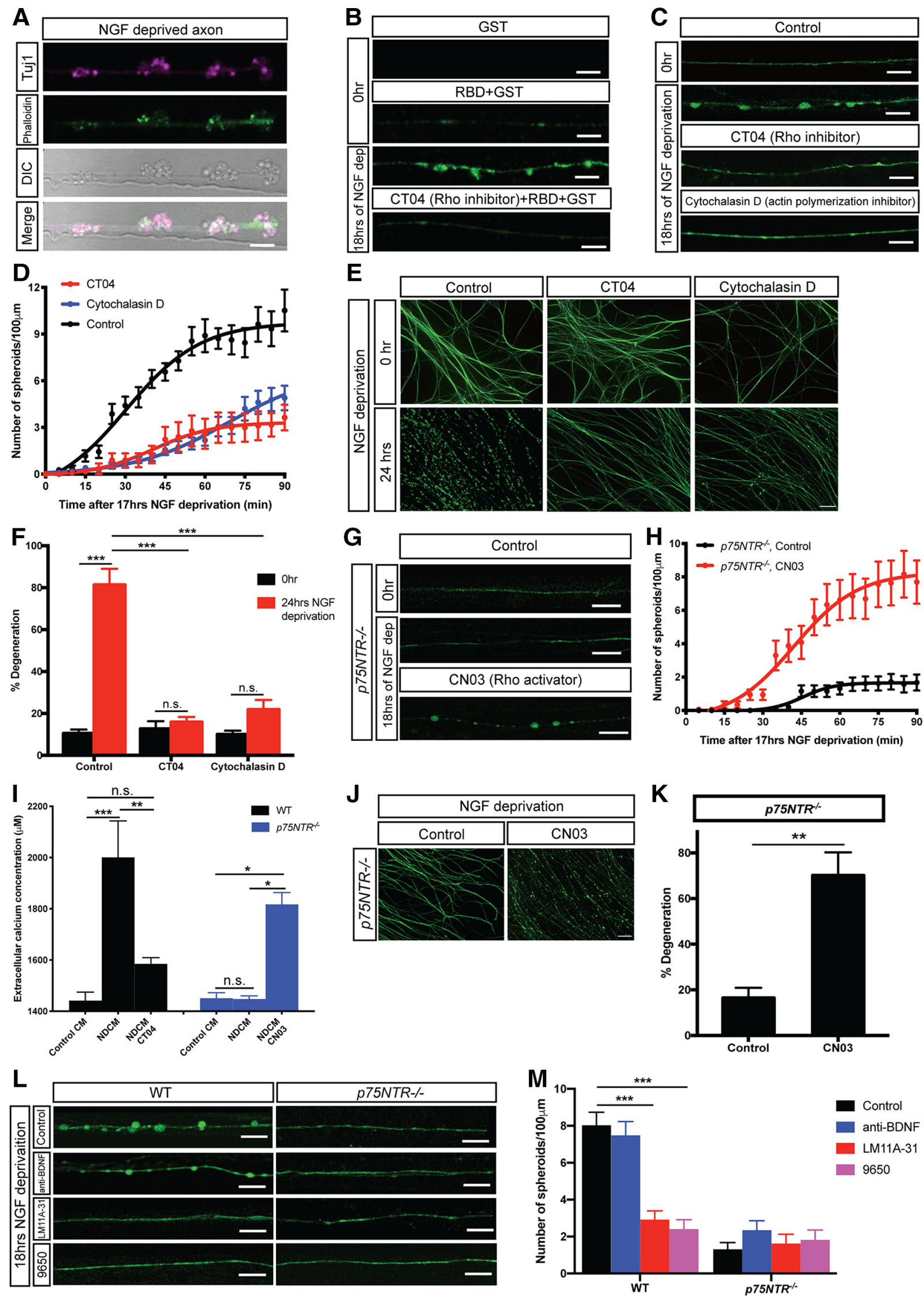

Figure 6. p75NTR-Rho signaling is required for axonal spheroid formation. A, Representative axons/spheroids visualized for $\beta 3$-tubulin (Tuj1), Phalloidin, and DIC after $18 \mathrm{~h}$ of NGF deprivation. Scale bar, $5 \mu \mathrm{m}$. B, Representative images of WT sympathetic axons immunostained for GST tag with or without NGF deprivation. All images, except the first one, show axons incubated with Rhotekin-RBD GST-fusion protein that binds active Rho proteins after fixation. Bottom, Axon was NGF-deprived and treated with $1 \mu \mathrm{g} / \mathrm{ml}$ Rho inhibitor CT04 for $3 \mathrm{~h}$. (Figure legend continues.) 
played $12.0 \pm 1.0$ and $6.1 \pm 0.7$ spheroids per $100 \mu \mathrm{m}$ of axons, respectively (Fig. $5 A, D$ ). However, $p 75 N_{T R}{ }^{-/-}$neurons displayed an $\sim 2 \mathrm{~h}$ delay in spheroid formation (Fig. $5 D$ ), which is consistent with delayed onset of catastrophic degeneration (Gamage et al., 2017). We also observed that loss of DR6 displayed an $\sim 800 \%$ increase in spheroid size after trophic deprivation similar to WT controls, whereas $p 75 \mathrm{NTR}^{-/-}$neurons displayed a delayed accumulation of spheroids with a total size increase of $<300 \%$ (Fig. $5 C$ ). If spheroid formation is a prerequisite for membrane rupture, NGF-deprived neurons isolated from $p 75 \mathrm{NTR}^{-/-}$mice would show diminished extracellular calcium expulsion, whereas $D R 6^{-1-}$ would display normal calcium release, a surrogate for membrane rupture. Indeed, $p 75 N T R^{-/-}$axons showed no difference in extracellular calcium levels before or after $18 \mathrm{~h}$ of NGF deprivation, whereas $D R 6^{-1-}$ neurons displayed a modest but significant increase (Fig. $5 E$ ). We next examined whether NGFdeprived conditioned media from $p 75 \mathrm{NTR}^{-/-}$or $D R 6^{-/-}$neurons were capable of inducing degeneration of WT axons (Fig. $5 G)$. Consistent with calcium release phenotypes, we found that NDCM derived from $p 75 \mathrm{NTR}^{-/-}$axons was incapable of inducing degeneration in WT axons (Fig. $5 H, I$ ). In contrast, NDCM from $D R 6^{-/-}$neurons contains prodegenerative activity (Fig.

\section{$\leftarrow$}

(Figure legend continued.) Scale bar, $5 \mu \mathrm{m}$. C, Fluo4-AM calcium imaging of WT sympathetic axons with or without drug treatment. For the CT04 group, WT axons were incubated in SCG media containing $1 \mu \mathrm{g} / \mathrm{ml}$ Rho inhibitor CT04, for $2 \mathrm{~h}$ before $17 \mathrm{~h}$ of NGF deprivation. For the cytochalasin D group, WT axons were incubated in SCG media containing $10 \mu \mathrm{g} / \mathrm{ml}$ actin polymerization inhibitor for $2 \mathrm{~h}$ before $17 \mathrm{~h}$ of NGF deprivation. Scale bar, $10 \mu \mathrm{m}$. D, Quantification of axonal spheroid number per $100 \mu \mathrm{m}$ of WT sympathetic axons at indicated time points after $17 \mathrm{~h}$ of NGF deprivation in the absence and presence of CTO4 or cytochalasin D. Total number of $n=9$ (Control), $n=8$ (CT04), and $n=22$ (cytochalasin D) axons from cultured neurons harvested from three independent litters were quantified. Nonlinear regression curves were drawn according to the Hill equation. $\boldsymbol{E}, \boldsymbol{F}$, Representative images $(\boldsymbol{E})$ and quantification $(\boldsymbol{F})$ of WT distal sympathetic axons immunostained for $\beta 3$-tubulin in the absence and presence of CT04 or cytochalasin D. Scale bar, $50 \mu \mathrm{m}$. Compared with $0 \mathrm{~h}, p<0.0001, n=3$ for Control, $24 \mathrm{~h} ; p=0.9256, n=7$ for CT04, $24 \mathrm{~h} ; p=0.1058, n=6$ for cytochalasin D, $24 \mathrm{~h}$ (two-way ANOVA with Sidak's multiple-comparisons test). Compared with Control, $24 \mathrm{~h}, p<0.0001$ for CT04, $24 \mathrm{~h} ; p<0.0001$ for cytochalasin D, $24 \mathrm{~h}$ (two-way ANOVA with Dunnett's multiplecomparisons test). G, Fluo4-AM calcium imaging of $p 75 \mathrm{NTR}^{-1-}$ sympathetic axons grown in the presence or absence of NGF with or without CN03 treatment. For the CNO3 group, p75NTR ${ }^{-1-}$ axons were incubated in SCG media containing $1 \mu \mathrm{g} / \mathrm{ml}$ Rho activator $\mathrm{CN} 03$ for $2 \mathrm{~h}$ before $17 \mathrm{~h}$ of NGF deprivation. Scale bar, $10 \mu \mathrm{m}$. $\boldsymbol{H}$, Quantification of number of spheroids per $100 \mu \mathrm{m}$ of $p 75$ NTR $^{-/-}$sympathetic axons at indicated time points after $17 \mathrm{~h}$ of NGF deprivation in the absence and presence of CNO3. Individual axons were counted: $n=16$ ( $p 75$ NTR $^{-/-}$, Control) and $n=12$ (p75NTR ${ }^{-/-}$, CN03) axons from three independent replicates. Nonlinear regression curves were drawn according to the Hill equation. $I$, Measurement of extracellular calcium concentration of untreated and NGF-deprived conditioned media in the presence and absence of CT04 or CNO3 collected from WT (black) and p75NTR ${ }^{-1-}$ (blue) sympathetic axons. Compared with WT, Control CM $(n=4), p<0.0001, n=4$ for WT, NDCM; $p=$ $0.4701, n=6$ for WT, NDCM CT04. Compared with WT NDCM, $p=0.0004$ for WT, NDCM CT04. Compared with p75NTR ${ }^{-1-}$, Control CM $(n=4), p>0.9999, n=5$ for $p 75$ NTR $^{-1-}$, NDCM; $p=0.0088, n=3$ for $p 75 N^{-1-} R^{-}$, NDCM CN03. Compared with $p 75 N_{T R}{ }^{-1-}$, NDCM, $p=$ 0.0055 for $p 75$ NTR $^{-\prime-}$, NDCM CN03 (one-way ANOVA with Tukey's multiple-comparisons test). $\boldsymbol{J}, \boldsymbol{K}$, Representative images $(\boldsymbol{J})$ and quantification $(\boldsymbol{K})$ of $p 75 N \mathrm{NR}^{-1-}$ distal sympathetic axons immunostained for $\beta 3$-tubulin after treatment with or without CN03 for $5 \mathrm{~h}$. All cell cultures were pretreated with $12 \mathrm{~h}$ of NGF deprivation. Scale bar, $50 \mu \mathrm{m} . p=0.0006, n=3$ for CNO3 and $n=7$ for control (unpaired $t$ test). $L, M$, Flu04-AM calcium imaging $(L)$ and spheroid number per $100 \mu \mathrm{m}$ of WT and $p 75 N^{-1 R^{-1}}$ sympathetic axons $(\boldsymbol{M})$ after $18 \mathrm{~h}$ of NGF deprivation in the absence and presence of $20 \mu \mathrm{g} / \mathrm{ml}$ anti-BDNF, $2 \mathrm{ng} / \mathrm{ml}$ p75NTR ligand/functional blocker LM11A-31, or 9650 immune serum (1:100). Scale bar, $10 \mu \mathrm{m}$. Individual axons were counted: $n=15$ (WT, Control), $n=16$ (WT, anti-BDNF), $n=37$ (WT, LM11A-31), $n=22$ (WT, $9650), n=16$ (p75NTR $^{-/-}$, Control), $n=19$ (p75NTR ${ }^{-/-}$, anti-BDNF), $n=18$ $\left(p 75 N_{T R}{ }^{-/-}, \mathrm{LM} 11 \mathrm{~A}-31\right)$, and $n=16\left(p 75 \mathrm{NTR}^{-/-}, 9650\right)$ axons from three independent replicates. Significance is determined by two-way ANOVA with Dunnett's multiplecomparisons test. Data are mean \pm SEM. ${ }^{*} p<0.05,{ }^{* *} p<0.001,{ }^{* * *} p<0.0001$.
$5 H, I)$. Together, these data suggest that p75NTR, but not DR6, is upstream of spheroid formation and membrane rupture.

\section{p75NTR-Rho signaling is necessary and sufficient for spheroid formation and entry into catastrophic phase}

How does p75NTR regulate spheroid formation before the catastrophic phase of degeneration? Previous work has shown that neurotrophins regulate growth cone dynamics by suppressing RhoA activation that occurs through p75NTR signaling (Gehler et al., 2004). p75NTR promotes RhoA activation to mediate sympathetic axonal degeneration in response to degenerative triggers, such as myelin (Yamashita and Tohyama, 2003; Park et al., 2010). The major downstream target of Rho activation is actin remodeling. We observed actin and $\beta 3$-tubulin enrichment in axonal spheroids (Fig. 6A), similar to previous observations (Beirowski et al., 2010). Active Rho in axonal spheroids was detected by incubation with GST-rhotekin RBD fusion protein after $18 \mathrm{~h}$ of NGF deprivation but not in cultures treated with Rho inhibitor C3 transferase (CT04) (Fig. 6B). Moreover, inhibiting Rho family members using CT04 ( $1 \mu \mathrm{g} / \mathrm{ml}, 2 \mathrm{~h}$ before $17 \mathrm{~h} \mathrm{NGF}$ deprivation) prevented spheroid formation in WT axons (Fig. 6C,D). We next tested whether actin remodeling is required for spheroid formation. Indeed, the actin polymerization inhibitor cytochalasin $\mathrm{D}$ $(10 \mu \mathrm{g} / \mathrm{ml})$ inhibited spheroid formation (Fig. 6C,D). Consistent with this, axons treated with CT04 or cytochalasin D delayed degeneration for up to $24 \mathrm{~h}$ after NGF deprivation (Fig. 6E,F). Together, these data suggest that activation of Rho and actin remodeling is necessary for spheroid formation and entry into the catastrophic phase of degeneration. Another downstream effector of Rho is the Rho-associated protein kinase 1. During apoptosis, Rho-associated protein kinase 1 has been shown to be cleaved by caspase-3, resulting in constitutive kinase activity to promote phosphorylation of myosin light chain and membrane blebbing (Coleman et al., 2001; Sebbagh et al., 2001). This may explain our finding of suppressed spheroid formation after NGF deprivation in the presence of caspase inhibitor (Fig. $2 A, B$ ).

If Rho is downstream of p75NTR, ectopic activation of Rho would promote spheroid formation and axon degeneration in the absence of p75NTR. To test this, we incubated NGF-deprived p75NTR ${ }^{-1-}$ axons with Rho activator, $\mathrm{CN} 03(1 \mu \mathrm{g} / \mathrm{ml}, 2 \mathrm{~h}$ before $17 \mathrm{~h}$ NGF deprivation). CN03 rescued the diminished spheroid formation and extracellular calcium release through membrane rupture in $p 75 \mathrm{NTR}^{-1-}$ axons $18 \mathrm{~h}$ after NGF deprivation (Fig. $6 G-I)$. We also found that $\mathrm{CN} 03$ could rescue the timing of degeneration in the absence of $p 75 N T R$ (NGF deprived for $12 \mathrm{~h}$ with $\mathrm{CN} 03$ for the final $5 \mathrm{~h}$ ) (Fig. $6 \mathrm{~J}, \mathrm{~K}$ ). Together, these data suggest that p75NTR-Rho signaling is necessary and sufficient to promote spheroid formation and entry into the catastrophic phase of degeneration.

\section{p75NTR-dependent spheroid formation is ligand-dependent} We next sought to determine whether p75NTR requires ligand to induce spheroid formation. Application of LM11A-31, a small nonpeptide p75NTR modulator (Massa et al., 2006; Simmons et al., 2014), suppressed spheroid formation on WT sympathetic axons after NGF deprivation (Fig. $6 L, M$ ). Since there have been conflicting reports about whether LM11A-31 specifically blocks ligand binding (Massa et al., 2006; Xie et al., 2019), we also used the ligand-blocking antibody 9650 specific for p75NTR extracellular domain (Kraemer et al., 2014). Compared with control serum, 9650 significantly inhibited spheroid formation on WT sympathetic axons after NGF deprivation and did not show additive effect on $p 75 \mathrm{NTR}^{-1-}$ axons (Fig. $6 L, M$ ). However, block- 
A

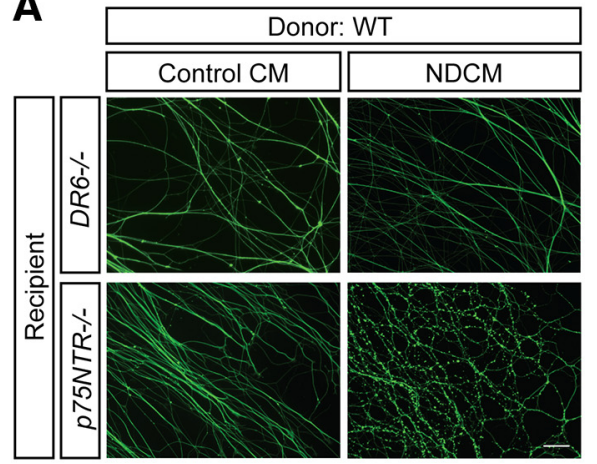

B

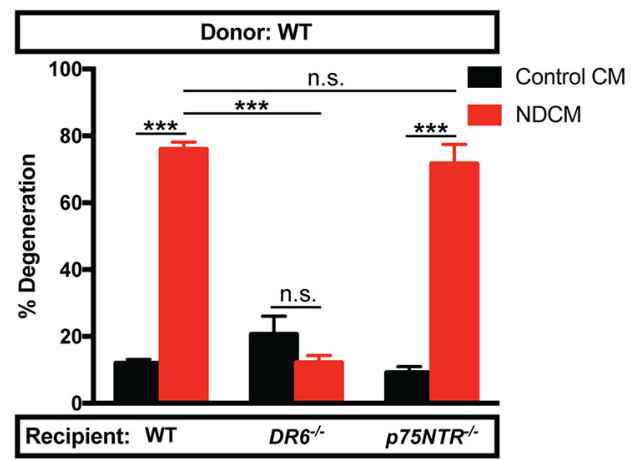

Figure 7. DR6 is required for catastrophic degeneration induced by NDCM. $A, B$, Representative images $(A)$ and quantification $(B)$ of distal sympathetic axons from DR6 ${ }^{-/-}$and $p 75 N T R^{-/-}$ animals immunostained for $\beta 3$-tubulin after treatment with NDCM and Control CM collected from WT neurons for $5 \mathrm{~h}$, respectively. All cultures were NGF-deprived for $12 \mathrm{~h}$ before the addition of $C M$. Left two columns represent percentages of degeneration of WT sympathetic axons treated with WT NDCM and Control CM, respectively. Compared with NDCM, $p<0.0001, n=10$ for WT, Control $\mathrm{CM} ; p=0.5437, n=3$ for DR6 ${ }^{-/-}$, Control CM; $p<0.0001, n=7$ for $p 75 N_{T R}{ }^{-1-}$, Control CM, two-way ANOVA with Sidak's multiple-comparisons test. Compared with WT, NDCM ( $\left.n=10\right)$, $p<$ $0.0001, n=9$ for $D R 6^{-/-}$, NDCM; $p=0.5422, n=11$ for $p 75$ NTR $^{-/-}$, NDCM, two-way ANOVA with Dunnett's multiple-comparisons test. Data are mean \pm SEM. ${ }^{* * *} p<0.0001$. Scale bar, 50 $\mu \mathrm{m}$.

ing BDNF, which has been shown to activate p75NTR apoptotic signaling (Kohn et al., 1999), failed to inhibit development of spheroids on NGF-deprived axons (Fig. $6 L, M$ ). These results suggest that p75NTR-mediated spheroid formation can be activated by binding prodegenerative ligands other than BDNF.

DR6, but not p75NTR, gates entry into the catastrophic phase of degeneration in response to NDCM

We next asked whether DR6 or p75NTR is downstream of the prodegenerative activity of NDCM using the paradigm described in Figure $4 A$. We applied NDCM collected from WT axons to recipient neurons derived from $D R 6^{-1-}$ and $p 75 N T R^{-1-}$ mice. After a $5 \mathrm{~h}$ treatment of NDCM, p75NTR ${ }^{-1-}$ axons showed $71.6 \pm 5.8 \%$ degeneration, whereas $D R 6^{-/-}$axons displayed minimal degeneration (Fig. $7 A, B$ ). These data suggest that DR6, but not p75NTR, is downstream of the prodegenerative effects of NDCM.

\section{Discussion}

By investigating calcium dynamics during the transition from latent to catastrophic phases of degeneration after trophic withdrawal, we identified several novel events: (1) Intraaxonal calcium rise and spheroid formation between latent and catastrophic phases of degeneration. This spheroid formation is triggered by p75NTR-Rho signaling, caspase activation, and actin remodeling. The timing of p75NTR-Rho-actin signaling and upregulation of prodegenerative transcriptional programs may define the duration of the latency phase. (2) The membranes of growing spheroids rupture, leading to expulsion of axoplasmic material to the extracellular environment. This may represent a novel mechanism by which prodegenerative molecules are released to influence neighboring cells. (3) The material expelled from ruptured spheroids triggers catastrophic degeneration. DR6 is required for responding to this prodegenerative signal, thereby gating entry into the catastrophic phase of degeneration (Fig. 8).

Formation of axonal spheroids has been reported in many neurological disorders, including Alzheimer's disease, amyotrophic lateral sclerosis, and neurocysticercosis (Griffin and Watson, 1988; Beirowski et al., 2010; Mejia Maza et al., 2019). After injury or oxidative stress, spheroids arise along the length of axons with accumulation of cytoskeleton degradation products and calcium overload (Beirowski et al., 2010; Barsukova et al., 2012). While spheroids have been extensively described in the literature, whether they have a function in promoting degeneration has remained unknown. We propose that the function of these spheroids is to trigger catastrophic degeneration by releasing prodegenerative molecules into the extracellular environment. Here, we report localized annexin V positivity (i.e., PS flipping) (Fig. $2 C$ ), which suggests that they are marked for phagocytic engulfment reminiscent of apoptotic bodies (Ravichandran, 2010; Segawa et al., 2014). Indeed, we observed several instances of spheroids detaching from the axon, which is a unit that presumably would be phagocytosed (Movie 4). Importantly, the exposure of PS on the outer leaflet of the spheroid membrane, but not the axon shaft, indicates that spheroids might be "hot-spots" on degenerating axons to recruit nearby glia or macrophages, clearing damaged components. In correlation with the growth of spheroids, we also observe that 3 and $10 \mathrm{kDa}$ fluorescent dextran entering the cytosol consistent with disrupted or ruptured plasma membrane (Fig. $3 B-D$ ). It is unclear where membrane integrity is disrupted; it may be at the belly of the spheroid and/or at axon/spheroid junctions. Whether or not spheroid rupture also occurs in aforementioned neurodegenerative disorders remains an open question.

What signaling pathways are upstream of spheroidal rupture? We found that disrupting caspase activation, p75NTR, Rho, or actin polymerization delays spheroid formation after NGF deprivation (Figs. $2 A, B, 6 C, D$ ). The intracellular domain of p75NTR has been shown to modulate RhoA activation by interacting with Rho GDP-dissociation inhibitor to inhibit axonal outgrowth and promote axon pruning (Yamashita et al., 1999, 2002; Park et al., 2010). In the presence of NGF, the interaction of p75NTR with Rho GDP-dissociation inhibitor-RhoA complex is disrupted, leading to RhoA inactivation and neurite outgrowth (Mathew et al., 2009). Consistent with these findings, we show that activation of RhoA in the absence of $p 75 N T R$ promotes entry into catastrophic phase by triggering spheroid formation (Fig. $6 G-K$ ). Proneurotrophin activation of p75NTR in the absence of Trk signaling leads to caspase-mediated neuronal death (Troy et al., 2002; Gentry et al., 2004). Sublethal executioner caspase activity plays an important role in nervous system development (Unsain and Barker, 2015). Interestingly, inhibition of caspases suppressed spheroid formation but failed to protect axons from NDCM-induced catastrophic degeneration (Fig. $4 F, G$ ). Thus, in the absence of NGF, spheroid formation is induced by p75NTR, 


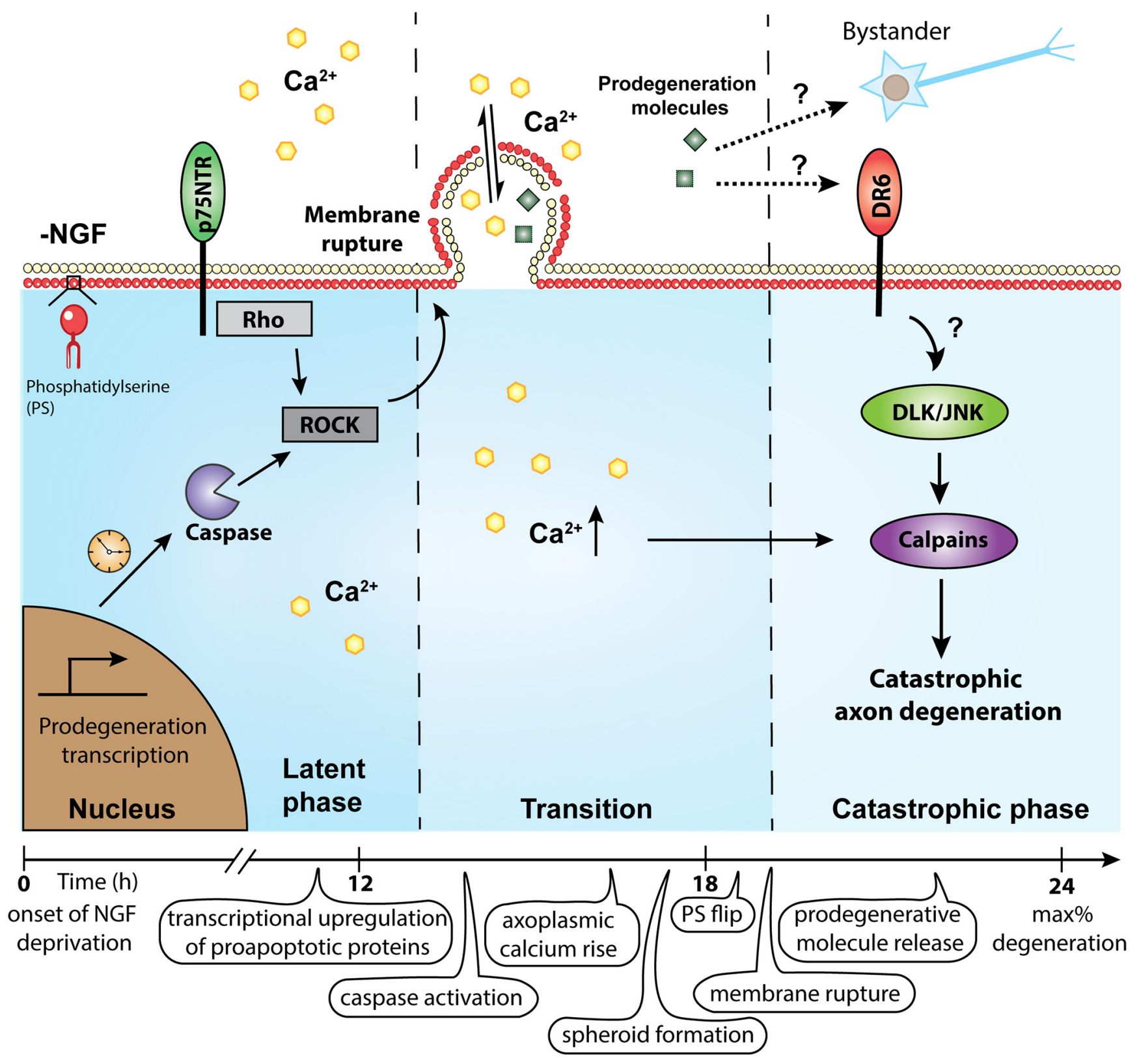

Figure 8. Time course of events associated with NGF deprivation-induced axon degeneration of sympathetic neurons. After NGF deprivation, prodegenerative transcription is upregulated. Axoplasmic calcium is increased and enriched in spheroids before catastrophic phase. Spheroid formation is regulated by p75NTR, Rho activity, and caspase activation. The calcium electrochemical gradient across the membrane is disrupted by spheroidal rupture, which may also lead to the release of intra-axonal prodegenerative molecules to extracellular space, acting as extrinsic factors to promote degeneration in a paracrine or autocrine manner. We speculate that p75NTR plays an important role in calcium dynamics during the latent phase, whereas DR6 can be activated by prodegenerative NDCM to mediate downstream catastrophic degeneration pathways (e.g., DLK/JNK, calpastatin, calpain).

caspase, RhoA, and actin remodeling, which are all requisite for transitioning from latent to catastrophic degeneration.

Our findings are consistent with the notion that p75NTR controls the window of latency before catastrophic degeneration. What is the molecular basis for the putative timer controlling the window of latency after trophic withdrawal? Classically, biological timers have been associated with transcriptional programs that form feedback loops (Mitrophanov and Groisman, 2008; Santos and Ferrell, 2008). Inhibition of transcription by applying actinomycin $\mathrm{D}$ to the soma during NGF deprivation blocked spheroid formation and degeneration (Fig. $2 A, B$ ), indicating the involvement of a degenerative transcriptional program. This pathway has been shown to upregulate $\mathrm{TNF} \alpha$-converting enzyme, which is necessary for p75NTR cleavage (Kenchappa et al.,
2010). Liberation of the p75NTR intracellular domain retrograde degenerative signal is accompanied by secondary activation of JNK and upregulation of proapoptotic factors, such as p53upregulated modulator of apoptosis (Kenchappa et al., 2010; Simon et al., 2016; Pathak et al., 2018). The time it takes to engage this transcriptional program and cleave p75NTR by TNF $\alpha$ converting enzyme and $\gamma$-secretase may represent a molecular timer governing the duration of the latency window (Pathak and Carter, 2017). This molecular timer may account for the delay of spheroid formation in NGF-deprived $p 75 N T R^{-/-}$axons (Fig. 5D).

What signaling pathways are downstream of spheroidal rupture? Similar to p75NTR, DR6 is required for axon degeneration after trophic withdrawal (Olsen et al., 2014; Gamage et al., 2017). Does DR6 regulate the same signaling events as p75NTR after 
trophic factor deprivation? We conclude that this is unlikely given that these TNFR family members govern distinct phases of degeneration. Unlike $p 75 N T R^{-/-}, D R 6^{-/-}$axons are capable of expelling prodegenerative axoplasmic materials to the surrounding environment via membrane rupture after NGF deprivation (Fig. $5 \mathrm{H}, \mathrm{I}) . \mathrm{DR6^{-1- }}$ axons are protected from entry into catastrophic phase in response to a $5 \mathrm{~h}$ incubation of NDCM (Fig. $7 A, B)$. These findings suggest that DR6 is downstream of spheroidal rupture and the destructive factor(s) found in NDCM; however, whether there is a direct or indirect interaction between these factors and DR6 remains to be determined. DR6 was previously shown to interact with $\beta$-APP to regulate developmental axonal pruning and synapse restriction (Nikolaev et al., 2009; Kallop et al., 2014). Given the fact that depletion of APP could partially protect sensory axons from degeneration after NGF withdrawal (Olsen et al., 2014), it is possible that DR6 promotes developmental catastrophic degeneration via an APP-dependent pathway. Previous findings show that DR6 potently activates NF- $\kappa \mathrm{B}$ and JNK to induce apoptosis (Benschop et al., 2009; Hu et al., 2014). Consistent with this, loss of DR6 suppressed phosphorylation of JNK after injury (Gamage et al., 2017). Thus, we speculate that direct or indirect activation of DR6 by the prodegenerative factor emanating from ruptured spheroids may promote the activation of JNK and calpain, which are known to trigger catastrophic degeneration (Fig. 8). It is also possible that activation of DR6 independently activates catastrophic degeneration by engagement of receptor-mediated caspase pathways.

Although the calcium-dependent protease, calpain, is known to be required for catastrophic degeneration (Fig. $4 F, G$ ), it is unclear why the initial intracellular wave of calcium before catastrophic degeneration is insufficient to trigger this event. One clue may come from Tessier Lavigne and colleagues who suggest that depletion of the calpain inhibitor, calpastatin, is required for catastrophic degeneration (Yang et al., 2013). The membrane ruptures that we observe at the onset of catastrophic degeneration is likely to cause equilibration of external and internal calcium concentrations. After rupture, intraxonal calcium levels are likely to be persistently high. However, depletion of calpastatin is likely prerequisite for calcium-dependent catastrophic degeneration. Recent studies show that chelation of extracellular calcium by EGTA in late, but not early, phases of degeneration rescues axons from trophic deprivation-induced degeneration (Johnstone et al., 2019). Additionally, the transient receptor potential vanilloid family member 1 cation channel is required for calcium influx to promote developmental sensory axon degeneration, whereas plasma membrane nanoruptures allow entry of extracellular calcium to drive axon degeneration in multiple sclerosis (Johnstone et al., 2019; Witte et al., 2019). Thus, extracellular calcium may enter the axoplasma via calcium channels, such as transient receptor potential vanilloid family member 1 or spheroidal ruptures. Both routes of sustained intracellular calcium elevation converge on calpain to trigger catastrophic degeneration.

In conclusion, our data reveal novel signaling emanating from two different death receptors to govern latent and catastrophic phases of degeneration. After NGF deprivation, prodegenerative transcription, caspase activation, and p75NTR-Rho-dependent actin remodeling promote formation of axonal spheroids. Axoplasmic materials containing prodegenerative molecules, such as calcium, are then released to the extracellular space via membrane rupture, which may act as a positive feedback loop to hasten the entry of axons into catastrophic phase degeneration. Entry into the catastrophic phase of degeneration appears to be gated by DR6 (Fig. 8). Whether or not this represents a mech- anism whereby axons might coordinate their degeneration requires further study. Nevertheless, the notion of destructive spheroids and subsequent interaxonal communication during degeneration facilitates our understanding of neural refinement during development and presents intriguing possibilities with respect to therapeutic intervention to alleviate bystander degeneration in disease.

\section{References}

Avery MA, Rooney TM, Pandya JD, Wishart TM, Gillingwater TH, Geddes JW, Sullivan PG, Freeman MR (2012) WldS prevents axon degeneration through increased mitochondrial flux and enhanced mitochondrial $\mathrm{Ca}^{2+}$ buffering. Curr Biol 22:596-600.

Bamji SX, Majdan M, Pozniak CD, Belliveau DJ, Aloyz R, Kohn J, Causing CG, Miller FD (1998) The p75 neurotrophin receptor mediates neuronal apoptosis and is essential for naturally occurring sympathetic neuron death. J Cell Biol 140:911-923.

Bano D, Munarriz E, Chen HL, Ziviani E, Lippi G, Young KW, Nicotera P (2007) The plasma membrane $\mathrm{Na}+/ \mathrm{Ca}^{2+}$ exchanger is cleaved by distinct protease families in neuronal cell death. Ann N Y Acad Sci 1099: 451-455.

Barsukova AG, Forte M, Bourdette D (2012) Focal increases of axoplasmic $\mathrm{Ca}^{2+}$, aggregation of sodium-calcium exchanger, $\mathrm{N}$-type $\mathrm{Ca}^{2+}$ channel, and actin define the sites of spheroids in axons undergoing oxidative stress. J Neurosci 32:12028-12037.

Beirowski B, Nógrádi A, Babetto E, Garcia-Alias G, Coleman MP (2010) Mechanisms of axonal spheroid formation in central nervous system Wallerian degeneration. J Neuropathol Exp Neurol 69:455-472.

Benschop R, Wei T, Na S (2009) Tumor necrosis factor receptor superfamily member 21: TNFR-related death receptor-6, DR6. Adv Exp Med Biol 647:186-194.

Brini M, Carafoli E (2011) The plasma membrane $\mathrm{Ca}^{2+}$ ATPase and the plasma membrane sodium calcium exchanger cooperate in the regulation of cell calcium. Cold Spring Harb Perspect Biol 3:a004168.

Campenot RB (1977) Local control of neurite development by nerve growth factor. Proc Natl Acad Sci U S A 74:4516-4519.

Chen M, Maloney JA, Kallop DY, Atwal JK, Tam SJ, Baer K, Kissel H, Kaminker JS, Lewcock JW, Weimer RM, Watts RJ (2012) Spatially coordinated kinase signaling regulates local axon degeneration. J Neurosci 32: $13439-13453$

Clapham DE (2007) Calcium signaling. Cell 131:1047-1058.

Coleman M (2005) Axon degeneration mechanisms: commonality amid diversity. Nat Rev Neurosci 6:889-898.

Coleman ML, Sahai EA, Yeo M, Bosch M, Dewar A, Olson MF (2001) Membrane blebbing during apoptosis results from caspase-mediated activation of ROCK I. Nat Cell Biol 3:339-345.

Cusack CL, Swahari V, Hampton Henley W, Michael Ramsey J, Deshmukh M (2013) Distinct pathways mediate axon degeneration during apoptosis and axon-specific pruning. Nat Commun 4:1876.

Deckwerth TL, Johnson EM Jr (1993) Temporal analysis of events associated with programmed cell death (apoptosis) of sympathetic neurons deprived of nerve growth factor. J Cell Biol 123:1207-1222.

Deppmann CD, Mihalas S, Sharma N, Lonze BE, Niebur E, Ginty DD (2008) A model for neuronal competition during development. Science 320:369373.

Edwards SN, Buckmaster AE, Tolkovsky AM (1991) The death programme in cultured sympathetic neurones can be suppressed at the posttranslational level by nerve growth factor, cyclic AMP, and depolarization. J Neurochem 57:2140-2143.

Gamage KK, Cheng I, Park RE, Karim MS, Edamura K, Hughes C, Spano AJ, Erisir A, Deppmann CD (2017) Death receptor 6 promotes Wallerian degeneration in peripheral axons. Curr Biol 27:890-896.

Geden MJ, Romero SE, Deshmukh M (2019) Apoptosis versus axon pruning: molecular intersection of two distinct pathways for axon degeneration. Neurosci Res 139:3-8.

Gehler S, Gallo G, Veien E, Letourneau PC (2004) p75 neurotrophin receptor signaling regulates growth cone filopodial dynamics through modulating RhoA activity. J Neurosci 24:4363-4372.

Gentry JJ, Barker PA, Carter BD (2004) The p75 neurotrophin receptor: multiple interactors and numerous functions. Prog Brain Res 146:25-39.

George EB, Glass JD, Griffin JW (1995) Axotomy-induced axonal degener- 
ation is mediated by calcium influx through ion-specific channels. J Neurosci 15:6445-6452.

Griffin JW, Watson DF (1988) Axonal transport in neurological disease. Ann Neurol 23:3-13.

Griffiths I, Klugmann M, Anderson T, Yool D, Thomson C, Schwab MH, Schneider A, Zimmermann F, McCulloch M, Nadon N, Nave KA (1998) Axonal swellings and degeneration in mice lacking the major proteolipid of myelin. Science 280:1610-1613.

Hamburger V, Oppenheim RW (1990) Naturally occurring neuronal death in vertebrates. In: Neuroembryology, pp 126-142. Boston: Birkhäuser.

Hendry IA, Campbell J (1976) Morphometric analysis of rat superior cervical ganglion after axotomy and nerve growth factor treatment. J Neurocytol 5:351-360.

Hu R, Du Q, Yin X, Li J, Wang T, Zhang L (2014) Agonist antibody activates death receptor 6 downstream signaling involving TRADD recruitment. FEBS Lett 588:401-407.

Johnstone AD, de Léon A, Unsain N, Gibon J, Barker PA (2019) Developmental axon degeneration requires TRPV1-dependent $\mathrm{Ca}^{2+}$ influx. eNeuro 6:ENEURO.0019-19.2019.

Kallop DY, Meilandt WJ, Gogineni A, Easley-Neal C, Wu T, Jubb AM, Yaylaoglu M, Shamloo M, Tessier-Lavigne M, Scearce-Levie K, Weimer RM (2014) A death receptor 6-amyloid precursor protein pathway regulates synapse density in the mature CNS but does not contribute to Alzheimer's disease-related pathophysiology in murine models. J Neurosci 34:6425-6437.

Kanamori T, Kanai MI, Dairyo Y, Yasunaga K, Morikawa RK, Emoto K (2013) Compartmentalized calcium transients trigger dendrite pruning in drosophila sensory neurons. Science 340:1475-1478.

Kantor DB, Kolodkin AL (2003) Curbing the excesses of youth. Neuron 38:849-852.

Kenchappa RS, Tep C, Korade Z, Urra S, Bronfman FC, Yoon SO, Carter BD (2010) p75 neurotrophin receptor-mediated apoptosis in sympathetic neurons involves a biphasic activation of JNK and up-regulation of tumor necrosis factor-alpha-converting enzyme/ADAM17. J Biol Chem 285: $20358-20368$.

Kohn J, Aloyz RS, Toma JG, Haak-Frendscho M, Miller FD (1999) Functionally antagonistic interactions between the TrkA and p75 neurotrophin receptors regulate sympathetic neuron growth and target innervation. J Neurosci 19:5393-5408.

Kraemer BR, Snow JP, Vollbrecht P, Pathak A, Valentine WM, Deutch AY, Carter BD (2014) A role for the p75 neurotrophin receptor in axonal degeneration and apoptosis induced by oxidative stress. J Biol Chem 289: 21205-21216.

Kristiansen M, Ham J (2014) Programmed cell death during neuronal development: the sympathetic neuron model. Cell Death Differ 21:1025-1035.

LaFerla FM (2002) Calcium dyshomeostasis and intracellular signalling in Alzheimer's disease. Nat Rev Neurosci 3:862-872.

Luo L, O'Leary DD (2005) Axon retraction and degeneration in development and disease. Annu Rev Neurosci 28:127-156.

Ma M, Ferguson TA, Schoch KM, Li J, Qian Y, Shofer FS, Saatman KE, Neumar RW (2013) Calpains mediate axonal cytoskeleton disintegration during Wallerian degeneration. Neurobiol Dis 56:34-46.

Maor-Nof M, Romi E, Sar Shalom H, Ulisse V, Raanan C, Nof A, Leshkowitz D, Lang R, Yaron A (2016) Axonal degeneration is regulated by a transcriptional program that coordinates expression of pro- and antidegenerative factors. Neuron 92:991-1006.

Massa SM, Xie Y, Yang T, Harrington AW, Kim ML, Yoon SO, Kraemer R, Moore LA, Hempstead BL, Longo FM (2006) Small, nonpeptide p75NTR ligands induce survival signaling and inhibit proNGF-induced death. J Neurosci 26:5288-5300.

Mathew SJ, Haubert D, Krönke M, Leptin M (2009) Looking beyond death: a morphogenetic role for the TNF signalling pathway. J Cell Sci 122:19391946.

Mattson MP (2007) Calcium and neurodegeneration. Aging Cell 6:337-350.

Mejia Maza A, Carmen-Orozco RP, Carter ES, Dávila-VillacortaDG, Castillo G, Morales JD, Mamani J, Gavídia C, Alroy J, Sterling CR, Gonzalez AE, García HH, Woltjer RL, Verástegui MR, Gilman RH (2019) Axonal swellings and spheroids: a new insight into the pathology of neurocysticercosis. Brain Pathol 29:425-436.

Mitrophanov AY, Groisman EA (2008) Positive feedback in cellular control systems. Bioessays 30:542-555.

Nikolaev A, McLaughlin T, O’Leary DD, Tessier-Lavigne M (2009) APP binds DR6 to trigger axon pruning and neuron death via distinct caspases. Nature 457:981-989.

Olsen O, Kallop DY, McLaughlin T, Huntwork-Rodriguez S, Wu Z, Duggan CD, Simon DJ, Lu Y, Easley-Neal C, Takeda K, Hass PE, Jaworski A, O'Leary DD, Weimer RM, Tessier-Lavigne M (2014) Genetic analysis reveals that amyloid precursor protein and death receptor 6 function in the same pathway to control axonal pruning independent of $\beta$-secretase. J Neurosci 34:6438-6447.

Park JW, Vahidi B, Taylor AM, Rhee SW, Jeon NL (2006) Microfluidic culture platform for neuroscience research. Nat Protoc 1:2128-2136.

Park KJ, Grosso CA, Aubert I, Kaplan DR, Miller FD (2010) p75NTRdependent, myelin-mediated axonal degeneration regulates neural connectivity in the adult brain. Nat Neurosci 13:559-566.

Pathak A, Carter BD (2017) Retrograde apoptotic signaling by the p75 neurotrophin receptor. Neuronal Signal 1:NS20160007.

Pathak A, Stanley EM, Hickman FE, Wallace N, Brewer B, Li D, Gluska S, Perlson E, Fuhrmann S, Akassoglou K, Bronfman F, Casaccia P, Burnette DT, Carter BD (2018) Retrograde degenerative signaling mediated by the p75 neurotrophin receptor requires p150Glued deacetylation by zxonal HDAC1. Dev Cell 46:376-387.e7.

Poon IK, Lucas CD, Rossi AG, Ravichandran KS (2014) Apoptotic cell clearance: basic biology and therapeutic potential. Nat Rev Immunol 14:166-180.

Probst A, Götz J, Wiederhold KH, Tolnay M, Mistl C, Jaton AL, Hong M, Ishihara T, Lee VM, Trojanowski JQ, Jakes R, Crowther RA, Spillantini MG, Bürki K, Goedert M (2000) Axonopathy and amyotrophy in mice transgenic for human four-repeat tau protein. Acta Neuropathol 99:469-481.

Purves D, Lichtman JW (1980) Elimination of synapses in the developing nervous system. Science 210:153-157.

Purves D, Snider WD, Voyvodic JT (1988) Trophic regulation of nerve cell morphology and innervation in the autonomic nervous system. Nature 336:123-128.

Ravichandran KS (2010) Find-me and eat-me signals in apoptotic cell clearance: progress and conundrums. J Exp Med 207:1807-1817.

Santos SD, Ferrell JE (2008) Systems biology: on the cell cycle and its switches. Nature 454:288-289.

Saxena S, Caroni P (2007) Mechanisms of axon degeneration: from development to disease. Prog Neurobiol 83:174-191.

Schindelin J, Arganda-Carreras I, Frise E, Kaynig V, Longair M, Pietzsch T, Preibisch S, Rueden C, Saalfeld S, Schmid B, Tinevez JY, White DJ, Hartenstein V, Eliceiri K, Tomancak P, Cardona A (2012) Fiji: an opensource platform for biological-image analysis. Nat Methods 9:676-682.

Sebbagh M, Renvoizé C, Hamelin J, Riché N, Bertoglio J, Bréard J (2001) Caspase-3-mediated cleavage of ROCK I induces MLC phosphorylation and apoptotic membrane blebbing. Nat Cell Biol 3:346-352.

Segawa K, Kurata S, Yanagihashi Y, Brummelkamp TR, Matsuda F, Nagata S (2014) Caspase-mediated cleavage of phospholipid flippase for apoptotic phosphatidylserine exposure. Science 344:1164-1168.

Simmons DA, Knowles JK, Belichenko NP, Banerjee G, Finkle C, Massa SM, Longo FM (2014) A small molecule p75NTR ligand, LM11A-31, reverses cholinergic neurite dystrophy in Alzheimer's disease mouse models with mid- to late-stage disease progression. PLoS One 9:e102136.

Simon DJ, Weimer RM, McLaughlin T, Kallop D, Stanger K, Yang J, O'Leary DD, Hannoush RN, Tessier-Lavigne M (2012) A caspase cascade regulating developmental axon degeneration. J Neurosci 32:17540-17553.

Simon DJ, Pitts J, Hertz NT, Yang J, Yamagishi Y, Olsen O, Tesic Mark M, Molina H, Tessier-Lavigne M (2016) Axon degeneration gated by retrograde activation of somatic pro-apoptotic signaling. Cell 164:1031-1045.

Singh KK, Park KJ, Hong EJ, Kramer BM, Greenberg ME, Kaplan DR, Miller FD (2008) Developmental axon pruning mediated by BDNF-p75NTRdependent axon degeneration. Nat Neurosci 11:649-658.

Takahashi T, Yagishita S, Amano N, Yamaoka K, Kamei T (1997) Amyotrophic lateral sclerosis with numerous axonal spheroids in the corticospinal tract and massive degeneration of the cortex. Acta Neuropathol 94:294-299.

Troy CM, Friedman JE, Friedman WJ (2002) Mechanisms of p75-mediated death of hippocampal neurons. role of caspases. J Biol Chem 277:3429534302 .

Twohig JP, Cuff SM, Yong AA, Wang EC (2011) The role of tumor necrosis factor receptor superfamily members in mammalian brain development, function and homeostasis. Rev Neurosci 22:509-533.

Unsain N, Barker PA (2015) New views on the misconstrued: executioner caspases and their diverse non-apoptotic roles. Neuron 88:461-474.

Vargas ME, Yamagishi Y, Tessier-Lavigne M, Sagasti A (2015) Live imaging 
of calcium dynamics during axon degeneration reveals two functionally distinct phases of calcium influx. J Neurosci 35:15026-15038.

Villegas R, Martinez NW, Lillo J, Pihan P, Hernandez D, Twiss JL, Court FA (2014) Calcium release from intra-axonal endoplasmic reticulum leads to axon degeneration through mitochondrial dysfunction. J Neurosci 34:7179-7189.

Wang JT, Medress ZA, Barres BA (2012) Axon degeneration: molecular mechanisms of a self-destruction pathway. J Cell Biol 196:7-18.

Wheeler MA, Heffner DL, Kim S, Espy SM, Spano AJ, Cleland CL, Deppmann CD (2014) TNF- $\alpha$ /TNFR1 signaling is required for the development and function of primary nociceptors. Neuron 82:587-602.

Witte ME, Schumacher AM, Mahler CF, Bewersdorf JP, Lehmitz J, Scheiter A, Sánchez P, Williams PR, Griesbeck O, Naumann R, Misgeld T, Kerschensteiner M (2019) Calcium influx through plasma-membrane nanoruptures drives axon degeneration in a model of multiple sclerosis. Neuron 101:615-624.e5.

Xie Y, Meeker RB, Massa SM, Longo FM (2019) Modulation of the p75 neurotrophin receptor suppresses age-related basal forebrain cholinergic neuron degeneration. Sci Rep 9:5273.
Yamashita T, Tohyama M (2003) The p75 receptor acts as a displacement factor that releases rho from rho-GDI. Nat Neurosci 6:461-467.

Yamashita T, Tucker KL, Barde YA (1999) Neurotrophin binding to the p75 receptor modulates rho activity and axonal outgrowth. Neuron 24:585-593.

Yamashita T, Higuchi H, Tohyama M (2002) The p75 receptor transduces the signal from myelin-associated glycoprotein to rho. J Cell Biol 157: $565-570$.

Yan T, Feng Y, Zheng J, Ge X, Zhang Y, Wu D, Zhao J, Zhai Q (2010) Nmnat2 delays axon degeneration in superior cervical ganglia dependent on its NAD synthesis activity. Neurochem Int 56:101-106.

Yang J, Weimer RM, Kallop D, Olsen O, Wu Z, Renier N, Uryu K, TessierLavigne M (2013) Regulation of axon degeneration after injury and in development by the endogenous calpain inhibitor calpastatin. Neuron 80:1175-1189.

Zhai Q, Wang J, Kim A, Liu Q, Watts R, Hoopfer E, Mitchison T, Luo L, He Z (2003) Involvement of the ubiquitin-proteasome system in the early stages of Wallerian degeneration. Neuron 39:217-225.

Zhang Y, Chen X, Gueydan C, Han J (2018) Plasma membrane changes during programmed cell deaths. Cell Res 28:9-21. 